Nathália Jucá Monteiro

Roteirização de Multi-Veículos e Multi-Produtos com Estoque e Transbordo:

Um Estudo de Caso

Dissertação de Mestrado

Dissertação apresentada ao Programa de Pós-Graduação em Engenharia de Produção da PUC-Rio como requisito parcial para obtenção do grau de Mestre em Engenharia de Produção.

Orientador: Prof. Hugo Miguel Varela Repolho

Co-orientador: Prof. Rafael Martinelli Pinto 


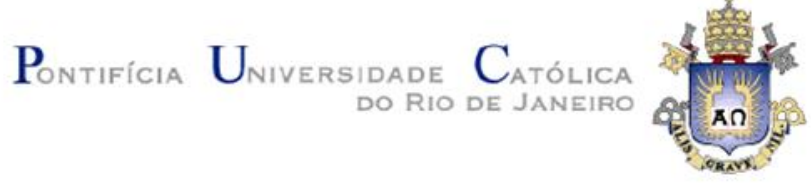

Nathália Jucá Monteiro

\title{
Roteirização de Multi-Veículos e Multi-Produtos com Estoque e Transbordo: Um Estudo de Caso
}

Dissertação apresentada como requisito parcial para obtenção do grau de Mestre pelo Programa de Pós-Graduação em Engenharia de Produção da PUC-Rio. Aprovada pela Comissão Examinadora abaixo assinada.

\author{
Prof. Hugo Miguel Varela Repolho \\ Orientador \\ Departamento de Engenharia Industrial - PUC-Rio \\ Prof. Rafael Martinelli Pinto \\ Co-orientador \\ Departamento de Engenharia Industrial - PUC-Rio
}

Prof. Silvio Hamacher

Departamento de Engenharia Industrial - PUC-Rio

Prof. Orivalde Soares da Silva Junior Departamento de Engenharia Industrial - PUC-Rio

Prof. Márcio da Silveira Carvalho Coordenador Setorial do Centro Técnico Científico - PUC-Rio

Rio de Janeiro, 31 de março de 2017 
Todos os direitos reservados. É proibida a reprodução total ou parcial do trabalho, sem autorização do autor, do orientador e da universidade.

\section{Nathália Jucá Monteiro}

Graduou-se em Engenharia de Produção pela Universidade do Estado do Pará (UEPA) em 2015. Durante a graduação atuou como estagiária do setor comercial na AMBEV, realizando atividades relacionadas ao acompanhamento de indicadores da empresa. Após a graduação, ingressou no Programa de Pós-Graduação em Engenharia de Produção da PUC-Rio para obtenção do título de mestre.

Ficha Catalográfica

Monteiro, Nathália Jucá

Roteirização de multi-veículos e multi-produtos com estoque e transbordo : um estudo de caso / Nathália Jucá Monteiro ; orientador: Hugo Miguel Varela Repolho ; coorientador: Rafael Martinelli Pinto. - 2017.

66 f. : il. color. ; $30 \mathrm{~cm}$

Dissertação (mestrado)-Pontifícia Universidade Católica do Rio de Janeiro, Departamento de Engenharia Industrial, 2017.

Inclui bibliografia

1. Engenharia Industrial - Teses. 2. Roteirização de veículos com estoque. 3. Transbordo. 4. Otimização. I. Repolho, Hugo Miguel Varela. II. Pinto, Rafael Martinelli. III. Pontifícia Universidade Católica do Rio de Janeiro. Departamento de Engenharia Industrial. IV. Título.

CDD: 658.5 


\section{Agradecimentos}

Agradeço à Deus e a Nossa Senhora de Fátima por terem sido fonte de conforto durante toda a caminhada desenvolvida.

Agradeço à minha família, Cícero, Rose e Nicole, por sempre terem acreditado em mim e por terem me incentivado a continuar mesmo nas horas mais difíceis.

Agradeço aos meus colegas de mestrado, por terem compartilhado essa caminhada comigo. Agradeço ao doutorando Igor Peres, o qual iniciou este trabalho e contribuiu para a sua continuação.

Agradeço ao professor Hugo Repolho e ao professor Rafael Martinelli pelo exemplo na orientação.

Ao CNPq e à PUC-Rio, pelos auxílios concedidos, sem os quais este trabalho não poderia ter sido realizado. 


\section{Resumo}

Monteiro, Nathália Jucá; Repolho, Hugo Miguel Varela (Orientador); Pinto, Rafael Martinelli (Co-orientador). Roteirização de Multi-Veículos e MultiProdutos com Estoque e Transbordo: Um Estudo de Caso. Rio de Janeiro, 2017. 66p. Dissertação de Mestrado - Departamento de Engenharia Industrial, Pontifícia Universidade Católica do Rio de Janeiro.

O transporte e os estoques correspondem a maior parte dos custos logísticos de uma empresa. Com o avanço da tecnologia, passou-se a analisar em conjunto esses dois componentes e não mais separados, como era feito anteriormente. O Problema de Roteirização de Veículos com Estoque (Inventory Routing Problem - IRP), nasceu dessa análise conjunta e procura encontrar a melhor rota para os veículos, atendendo a um determinado nível de estoque. Este trabalho apresenta um modelo de IRP com múltiplos veículos e produtos, onde existe a possibilidade de transbordo entre os centros de distribuição existentes. $O$ modelo desenvolvido foi elaborado em um estudo de caso real em uma empresa do setor varejista. Após sua elaboração, o modelo foi testado com uma instância menor e comparado a situação atual da empresa, a fim de testar sua eficiência. Em seguida, foi rodado com os dados completos da empresa, e foram analisados os resultados. Na resolução, foi utilizado o software Xpress, o qual utiliza programação inteira como método de resolução.

\section{Palavras - chave}

Roteirização de Veículos com Estoque; Transbordo; Otimização. 


\section{Abstract}

Monteiro, Nathália Jucá; Repolho, Hugo Miguel Varela (Advisor); Pinto, Rafael Martinelli (Co-advisor). Multi-Vehicles Multi-Products Inventory Routing Problem With Transshipment: A Case Study. Rio de Janeiro, 2017. 66p. Dissertação de Mestrado - Departamento de Engenharia Industrial, Pontifícia Universidade Católica do Rio de Janeiro.

Transport and inventories account for most of a company's logistics costs. With the advancement of technology, we began to analyze these two components together and no longer separate, as was done previously. The Inventory Routing Problem (IRP) was born from this joint analysis and seeks to find the best route for the vehicles, meeting a certain level of inventory. This work presents an IRP model with multiple vehicles and products, where there is the possibility of transshipment between existing distribution centers. The developed model was elaborated in a real case study in a company of the retail sector. After its elaboration, the model was tested with a smaller instance and compared to the current situation of the company in order to test its efficiency. It was then run with the complete company data, and the results were analyzed. In the resolution, Xpress software was used, which uses integer programming as the resolution method.

\section{Keywords}

Inventory Routing Problem; Transshipment; Optimization. 


\section{Sumário}

1. Introdução 11

1.1. Considerações Iniciais 11

1.2. Justificativa e Motivação 12

$\begin{array}{ll}\text { 1.3. Objetivos } & 14\end{array}$

1.4. Estrutura da Dissertação 14

2. Referencial Teórico 15

2.1. Gestão da Cadeia de Suprimentos $\quad 15$

2.2. Logística Empresarial 18

2.3. Distribuição Física 19

2.4. Roteirização de Veículos 20

2.4.1. Classificação dos Problemas de Roteirização 22

2.4.2. Roteirização de Veículos com Estoque (IRP) 24

2.4.3. Roteirização de Veículos com Estoque e Transbordo (IRPT) 26

3. Metodologia da Pesquisa 31

3.1. Caracterização e Delineamento da Pesquisa 31

3.1.1. Natureza da Pesquisa 31

3.1.2. Forma de Abordagem do Problema 31

3.1.3. Ponto de Vista dos Objetivos 31

3.1.4. Ponto de Vista dos Procedimentos Técnicos 32

3.2. Etapas da Concepção do Estudo 32

4. Modelo de Roteirização de Veículos com Estoque e Transbordo, IRPT

4.1. Caracterização do Problema 33

4.2. Formulação do Problema 33

4.3. Restrições de Eliminação de Subrotas 38

4.4. Validação do Modelo 39

4.5. Análise de Cenários $\quad 45$ 
5. Estudo de Caso 48

5.1. Apresentação da Empresa 48

5.2. Coleta e Tratamento dos Dados 49

5.3. Apresentação e Análise dos Resultados Obtidos 51

5.3.1. Resultado com 2 Períodos de Tempo 51

5.3.2. Resultado com Quatro Períodos de Tempo 54

5.4. Restrições de Corte no Xpress 57

6. Considerações Finais $\quad 60$

6.1. Considerações sobre os Resultados Obtidos 60

6.2. Propostas de Estudos Futuros 61

7. Referências bibliográficas 62 


\section{Lista de Figuras}

Figura 1 - Representatividade dos custos logísticos em relação ao PIB 12

Figura 2 - Graus de complexidade da cadeia de suprimentos 16

Figura 3 - Competição entre unidades de negócios 17

Figura 4 - Atividades da logística 19

Figura 5 - Representação genérica de um IRP 25

Figura 6 - Transbordo lateral $\quad 27$

Figura 7 - Pseudocódigo do algoritmo TSP 39

Figura 8 - Gráfico das soluções do teste 1

Figura 9 - Nível de estoque nos CD's no teste 1

Figura 10 - Gráfico das soluções do teste 2

Figura 11 - Nível de estoque nos CD's no teste 2

Figura 12 - Distribuição das soluções do cenário atual 46

Figura 13 - Distribuição dos estoques no cenário atual 46

Figura 14 - Distribuição das soluções do modelo com dois períodos de tempo 52

Figura 15 - Estoque no modelo de dois períodos 53

Figura 16 - Representação dos custos do modelo com dois períodos 53

Figura 17 - Distribuição das soluções do modelo com quatro períodos de tempo 55

Figura 18 - Estoque no modelo de quatro períodos 55

Figura 19 - Representação dos custos do modelo com quatro períodos 56

Figura 20 - Procedimento de SEC do TSP no software Xpress 58

Figura 21 - Pseudocódigo do modelo com o callback 59 


\section{Lista de Tabelas}

Tabela 1 - Características dos problemas de roteirização e programação 23

Tabela 2 - Conjuntos e índices $\quad 35$

Tabela 3 - Parâmetros 35

Tabela 4 - Variáveis $\quad 35$

Tabela 5 - Demanda de cada família de produto por CD no período de 7 dias (5.000 unidades) 40

Tabela 6 - Rotas geradas no teste 1

Tabela 7 - Rotas geradas no teste 2

Tabela 8 - Principais resultados comparativos entre o cenário atual e o proposto 47

Tabela 9 - Custos de transportes (em R\$) 49

Tabela 10 - Tempos de deslocamento (em dias) 50

Tabela 11 - Demanda de cada família de produto por CD no período de 7 dias (5.000 unidades) 50

Tabela 12 - Capacidade de armazenagem dos locais (unidades) 51

Tabela 13 - Rotas do modelo com dois períodos de tempo 53

Tabela 14 - Rotas do modelo com quatro períodos de tempo 56 


\section{Introdução}

O presente capítulo tem por finalidade apresentar algumas considerações iniciais e a justificativa e a motivação da pesquisa, bem como os objetivos que devem ser atingidos com a realização do trabalho e a forma como a pesquisa foi organizada.

\section{1.}

\section{Considerações Iniciais}

O aumento da competição entre as organizações tem forçado as empresas a expandir seus mercados em uma escala global. Essa expansão deve-se ao avanço da tecnologia, sendo que dentro desse contexto a logística passou a assumir um fator crítico nas cadeias de suprimentos, tornando os custos logísticos totais um dos mais importantes indicadores econômicos da eficiência de uma cadeia de suprimentos (ZENG e ROSSETTI, 2003).

Zeng e Rossetti (2003), destacam que os custos associados às atividades logísticas são divididos em: transporte, armazenagem, processamento do pedido, administração e manutenção de estoque. De acordo com uma pesquisa realizada pelo Instituto de Logística e Supply Chain (ILOS), em 2012, o Brasil apresentou custos logísticos de $11,5 \%$ do seu Produto Interno Bruto (PIB), enquanto que países desenvolvidos como os Estado Unidos gastaram 8,3\% do PIB no mesmo ano. Na Figura 1, apresenta-se a divisão dos custos logísticos ao longo dos anos.

Como pode ser observado na Figura 1, o transporte foi apontado como a maior fonte de gastos do PIB durante todo o período analisado, seguido pelos custos com estoque, armazenagem e custos administrativos. Gilmore (2002) também destaca que os custos de transporte representam um componente substancial, não somente da logística, mas também de uma cadeia de suprimentos.

O segundo componente responsável pela maior parte dos gastos são os estoques, os quais, segundo Slack et al. (2009) representam um grande dilema 
para os gestores, pois apesar de elevados custos e desvantagens associadas à sua manutenção, eles também facilitam a conciliação entre a oferta e a demanda.

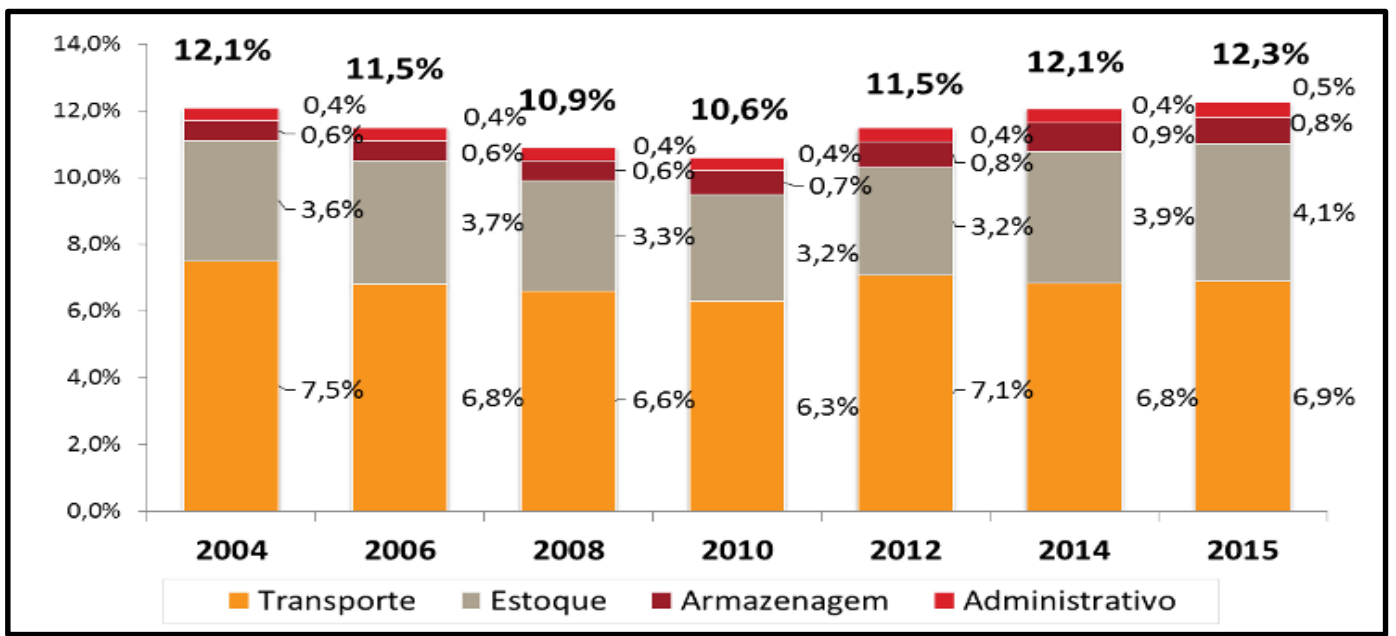

Figura 1 - Representatividade dos custos logísticos em relação ao PIB Fonte: ILOS (2017).

Diante desse cenário e em função do avanço da tecnologia, as empresas estão passando a tratar a gestão do transporte e dos estoques de uma forma conjunta, e não mais como aspectos distintos conforme era feito no passado. Cunha (2000) destaca que a roteirização de veículos envolve um conjunto muito diverso de problemas, sendo a roteirização de veículos com estoque somente um deles.

A junção desses dois componentes, transportes e estoque, dá origem a um problema de roteirização de veículos conhecido como Roteirização de Veículos com Estoque, no qual o fornecedor coordena o processo de reposição de produtos dos seus consumidores (COELHO e LAPORTE, 2013a). A designação do problema na literatura anglo-saxônica, Inventory Routing Problem, fornece as siglas pela qual o problema se popularizou, IRP.

Guemri et al. (2016) afirmam que o objetivo do IRP é minimizar os custos de distribuição e de estoque, ao mesmo tempo que algumas restrições são satisfeitas, como as relativas ao veículo e a capacidade de armazenagem das instalações.

\section{2.}

\section{Justificativa E Motivação}

Apesar da extensa literatura acerca do tema, foi observado pela autora a existência de uma lacuna na abordagem desse tipo de roteirização, já que a maioria dos artigos não aborda aspectos como a variedade dos produtos e de 
veículos de uma empresa, além da possibilidade de abastecimento por locais que estejam no mesmo nível da cadeia.

Em relação ao modelo desenvolvido nesta dissertação, o trabalho de Coelho et al. (2012) difere na forma de operar o transbordo. Enquanto aqui o transbordo é realizado pelos mesmos veículos que fazem a distribuição de fábrica, no Coelho et al. (2012) o transbordo é realizado entre centros de distribuição por veículos terceirizados. Desta forma, como as entregas são feitas por dois veículos diferentes, a capacidade do cliente pode ser excedida, temporariamente, em algum momento no tempo, o que não ocorre no modelo abordado nesta dissertação. Para além disso, o artigo em causa considera um veículo e produto únicos, contrariamente ao considerado nesta dissertação.

Guemri et al. (2016), também abordou o problema de IRP com múltiplos produtos e veículos, fato que se assemelha ao modelo desta dissertação. Contudo, o modelo da dissertação aborda o IRP com transbordo, o qual não foi apresentado em Guemri et al. (2016).

Mirzapour Al-e-Hashem e Rekik (2014) também trabalharam com o IRP e o modelo desenvolvido pelos autores também trabalha com múltiplos produtos, veículos com capacidades diferentes pertencentes a uma empresa terceirizada e uma demanda determinística e que varia com o tempo. O desta dissertação, excluindo o fato dos veículos pertencerem a uma empresa terceirizada, apresenta características semelhantes ao de Mirzapour Al-e-Hashem e Rekik (2014), contudo, o modelo desta dissertação utiliza uma restrição que elimina subrotas mais clássica a dos autores.

Dessa forma, o presente trabalho vem preencher essa lacuna, abordando no modelo, tanto a existência de múltiplos produtos e veículos como de transbordo em um problema de IRP.

Com base na situação exposta acima, é de interesse da autora desenvolver um modelo de roteirização que leve em consideração essa multiplicidade e outras possibilidades de abastecimento de um centro de distribuição, motivada pelo fato de poder contribuir para o aumento da literatura sobre os problemas de roteirização e realizar uma representação mais próxima da realidade de diversas empresas brasileiras.

Associada à situação já apresentada, pode-se formular a seguinte pergunta:

Quais os impactos causados nos roteiros gerados nos Problemas de Roteirização de Veículos quando são considerados, além dos custos de distribuição, os custos de estocagem e a possibilidade da ocorrência de transbordo? 


\section{3.}

\section{Objetivos}

O objetivo principal deste trabalho é propor um modelo matemático para a roteirização de veículos na distribuição física de mercadorias por uma frota de veículos originários de um fábrica para o abastecimento de vários centros de distribuição, levando em consideração a minimização dos custos de distribuição e de estocagem dos produtos, além da existência de transbordo entre os centros.

Para alcançar o objetivo principal exposto, serão considerados os objetivos específicos listados abaixo:

- Revisão da literatura dos modelos de IRP já existentes;

- Resolução do modelo matemático por meio da programação inteira-mista; - Aplicação do modelo proposto em um caso real de uma empresa produtora e distribuidora de cigarros localizada no Rio de Janeiro;

- Comparação do resultado gerado pelo modelo com a situação real da empresa.

\section{4 .}

\section{Estrutura Da Dissertação}

Além do presente capítulo, de caráter introdutório, esta dissertação é composta de mais cinco capítulos.

No Capítulo 2 aborda-se o referencial teórico utilizado para a realização do trabalho, levando em consideração temas de gestão da cadeia de suprimentos, logística empresarial, distribuição física e roteirização de veículos.

No Capítulo 3 realiza-se a caracterização e delineamento da pesquisa. Já no Capítulo 4 apresenta-se o modelo matemático, por meio da caracterização e formulação do problema, também foi feita a validação do modelo e uma análise de cenários, além de apresentar um breve referencial sobre as restrições de corte utilizadas no problema.

No Capítulo 5 é feito o estudo de caso, com a apresentação da empresa, coleta e tratamento dos dados e apresentação e análise dos resultados obtidos, bem como é explicada a forma como as restrições de corte foram implementadas no software Xpress.

O Capítulo 6 encerra esta dissertação com considerações sobre os resultados obtidos e propostas de trabalhos futuros. 


\section{Referencial Teórico}

Neste capítulo será realizado uma revisão de literatura com temas pertinentes para o desenvolvimento do trabalho, como a gestão da cadeia de suprimentos e roteirização de veículos, com destaque para a roteirização de veículos com estoque e transbordo.

Deve-se ressaltar que o objetivo deste capítulo não é aprofundar as discussões acerca dos temas citados, mas sim, situar o leitor nos assuntos mais relevantes para a realização da pesquisa.

\section{1.}

\section{Gestão Da Cadeia De Suprimentos}

Cada vez mais os clientes estão exigindo que os produtos sejam entregues mais rapidamente, no momento certo e sem defeitos, e essas exigências estão mudando a forma como as empresas se relacionam entre si e com seus fornecedores. Mentzer et al. (2001), afirmam que ter um produto livre de defeitos e entregue de forma mais rápida e confiável não é mais uma vantagem competitiva perante aos concorrentes, e sim um requisito para estar no mercado.

Diante desse cenário, no mercado moderno, as empresas não competem como entidades autônomas, mas sim como cadeias de suprimento (LAMBERT et al., 1998). Lambert et al. (1998), definem a cadeia de suprimentos (supply chains) como uma rede de múltiplos negócios e relacionamentos, a qual, segundo Bowersox e Closs (1996), constitui uma estrutura para operações e fornecedores, que quando combinados levam produtos, informações e prestação de serviço de forma eficiente ao consumidor final.

Mentzer et al. (2001) ressaltam que uma organização pode fazer parte de mais de uma cadeia de suprimentos, além de definir uma cadeia de suprimentos como um conjunto de três ou mais entidades diretamente envolvidas nos fluxos a montante e a jusante na entrega de um produto para o consumidor. Baseado neste conceito, os autores identificaram três graus de complexidade: cadeia de 
suprimentos direta, cadeia de suprimentos estendida e cadeia de suprimentos final. Na Figura 2 é possível observar como cada um dos graus funciona.

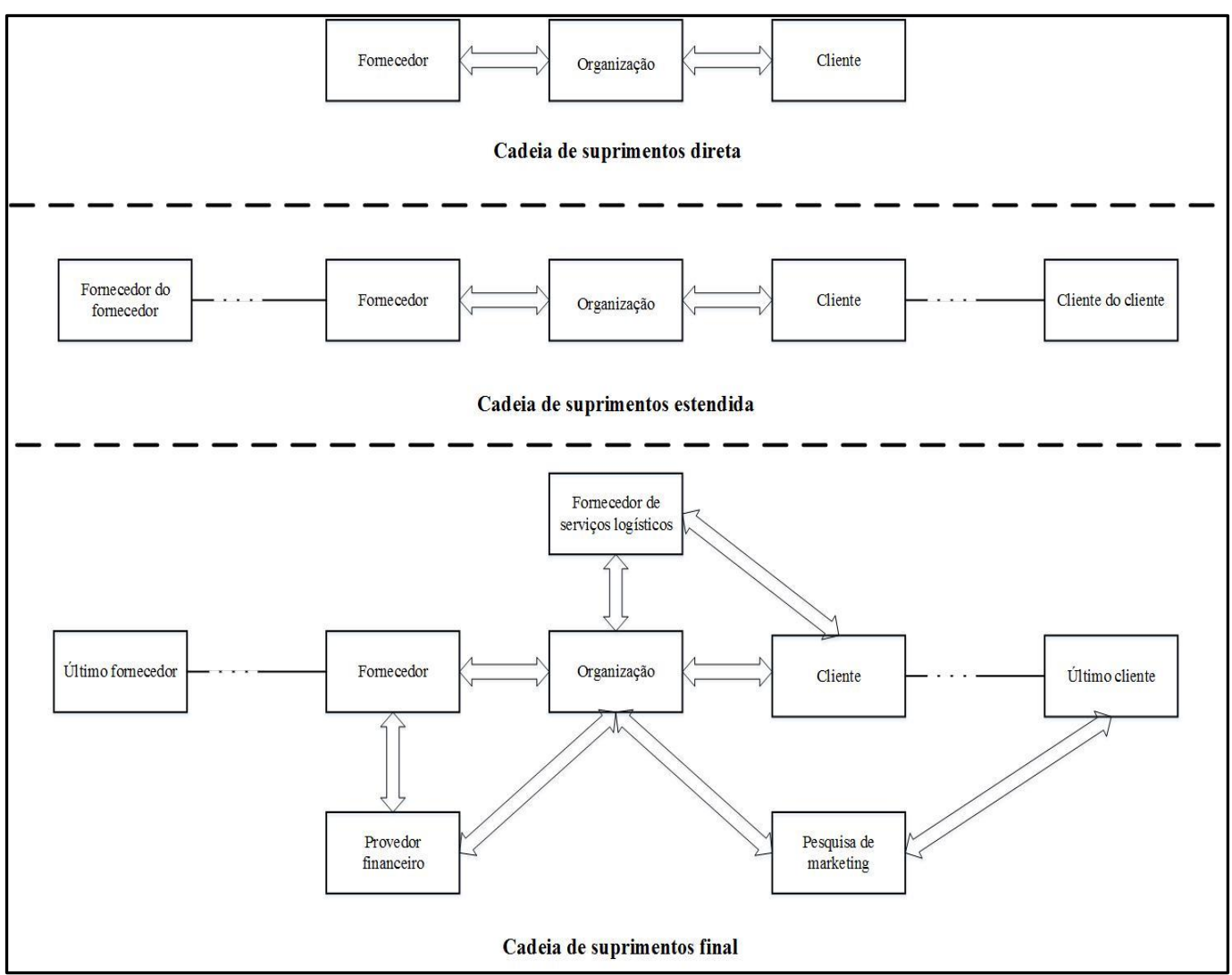

Figura 2 - Graus de complexidade da cadeia de suprimentos Fonte: Adaptado de Mentzer et al. (2001).

Na Figura 2, pode-se observar os três graus de complexidade mais comuns em uma cadeia de suprimentos, onde o primeiro é uma cadeia de suprimentos direta, no qual a empresa se relaciona somente com clientes e fornecedores diretos. O segundo representa uma cadeia estendida, no qual a organização além de ter relação com seus clientes e fornecedores diretos, também se relaciona com o fornecedor dos seus fornecedores e os clientes dos seus clientes. O terceiro é uma cadeia de suprimentos final, na qual a empresa interage com o último fornecedor e o último cliente, além de se relacionar com atividades terceirizadas do negócio, como marketing, operadores logísticos e serviços financeiros.

Diante desse cenário de múltiplos atores e relacionamentos, na década de 1980 surgiu o termo "gestão da cadeia de suprimentos" ou supply chain management (LAMBERT et al., 1998). A gestão da cadeia de suprimentos é responsável, segundo o CSCMP (2016) (Council of Supply Chain Management Professionals), pelo planejamento e gestão de todas as atividades envolvendo as compras, processamento e logística, além da colaboração e coordenação com os parceiros da organização. 
Pires (1998) destaca que o surgimento da gestão de cadeia de suprimentos, mudou os elementos de competição do mercado. Atualmente a competição ocorre entre cadeias produtivas (unidades virtuais de negócios) ao invés de entre empresas isoladas, conforme ilustrado na Figura 3.

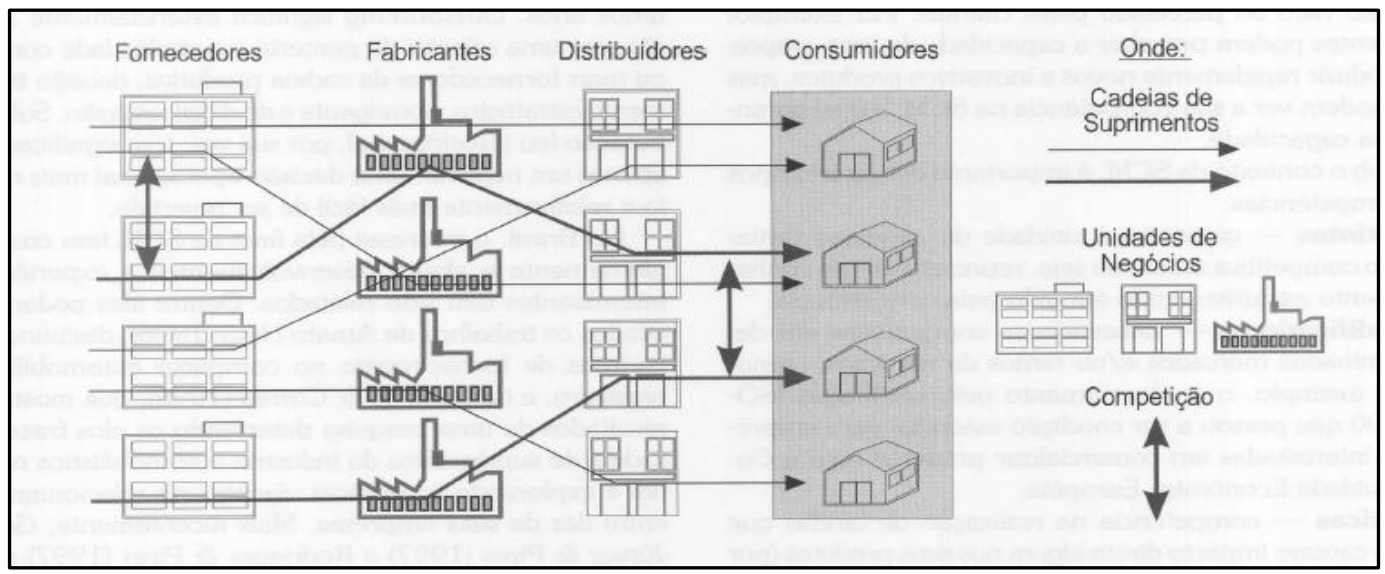

Figura 3 - Competição entre unidades de negócios Fonte: Pires (1998)

Thomas e Griffin (1996) dividem a cadeia de suprimentos em três estágios: aquisição, produção e distribuição, sendo que os componentes da cadeia podem estar localizados em diferentes partes do mundo, dificultando a coordenação na cadeia. Cooper et al. (1997), desenvolveram um framework conceitual da gestão da cadeia de suprimentos, sendo o framework composto dos processos de negócio, componentes de gestão e da estrutura da cadeia. Com a identificação desses elementos, torna-se possível conhecer melhor a cadeia e desenvolver sua integração da melhor forma.

Essa dissertação foi desenvolvida no nível operacional de uma cadeia de suprimentos, sendo esse nível definido em três categorias de coordenação por Thomas e Griffin (1996): comprador - vendedor, produção - distribuição e estoque - distribuição.

A categoria produção - distribuição foi a abordada neste trabalho, visto que engloba os problemas de roteirização de veículos. A distribuição de um produto pode acontecer de várias maneiras, contudo, são poucos os problemas que abordam as duas vertentes simultaneamente (THOMAS e GRIFFIN, 1996). Algumas das razões para a ausência de simultaneidades, são segundo Thomas e Griffin (1996), listadas abaixo:

- Alguns desses problemas são muito difíceis de se resolver isoladamente, aumentando a complexidade quando são combinados; 
- Na prática, essas duas etapas são, geralmente, separadas por pequenos estoques (pulmões);

- Departamentos distintos são responsáveis por essas atividades, não havendo o compartilhamento de informações.

Em resumo, as modificações no mercado forçaram as organizações a estabelecerem laços mais fortes com seus clientes e fornecedores. Todavia, essas parcerias resultam em problemas complexos e que devem ser estudados para um bom fluxo das mercadorias e informações.

\section{2.}

\section{Logística Empresarial}

A logística foi associada a atividades militares durante muitos séculos. As guerras eram longas e ocorriam em lugares afastados, o que exigia grande deslocamento. O planejamento da logística possibilitava a chegada de suprimentos, carros de guerra e batalhões de soldados aos locais de combate. Após a Segunda Guerra Mundial, aconteceu uma explosão de consumo nos EUA, devido à demanda reprimida nos anos de depressão. Nesta época, o objetivo empresarial era obter a maior margem de lucros possível, o que levou a logística a ser considerada como "a última fronteira" para a redução de custos, e ocasionou um grande avanço na melhoria dos processos logísticos (CASTIGLIONI, 2009).

A logística trata de todas as atividades de movimentação e armazenagem, as quais facilitam o fluxo dos produtos, desde o ponto de aquisição da matériaprima até o consumidor final, bem como dos fluxos de informações envolvidas, atendendo ao cliente com um nível de serviço adequado e um custo razoável (BALLOU, 2006). O conceito de logística pode ser definido pelo Council of Supply Chain Management Professionals apud Novaes (2004) como:

"Logística é o processo de planejar, implementar e controlar de maneira eficiente o fluxo e a armazenagem de produtos, bem como os serviços e informações associados, cobrindo desde o ponto de origem até o ponto de consumo, com o objetivo de atender aos requisitos do consumidor."

Alvarenga e Novaes (1994) ressaltam que a logística possui uma abordagem mais ampla que a distribuição física, pois também observa a fábrica, o local de estocagem, os níveis de inventário e os sistemas de informação, além do transporte e da armazenagem.

Rosa (2011) destaca que a logística gera um valor que pode ser expresso nas formas de tempo e lugar, ou seja, os produtos passam a possuir valor para o cliente quando (tempo) e onde (lugar) ele necessita do mesmo. Ainda segundo o 
mesmo autor, a logística utiliza vários tipos de modais de transporte para deslocar o produto até o cliente final, além disso, ela utiliza estoques bem distribuídos ao longo da sua região de atuação para melhorar seu processo de entrega e cumprir o prazo de entrega acordado com o cliente.

As atividades da logística são estabelecidas com base no nível de serviço, visto que ele se encontra no centro do processo logístico (ROSA, 2011). Na Figura 4 ilustram-se as atividades da logística.

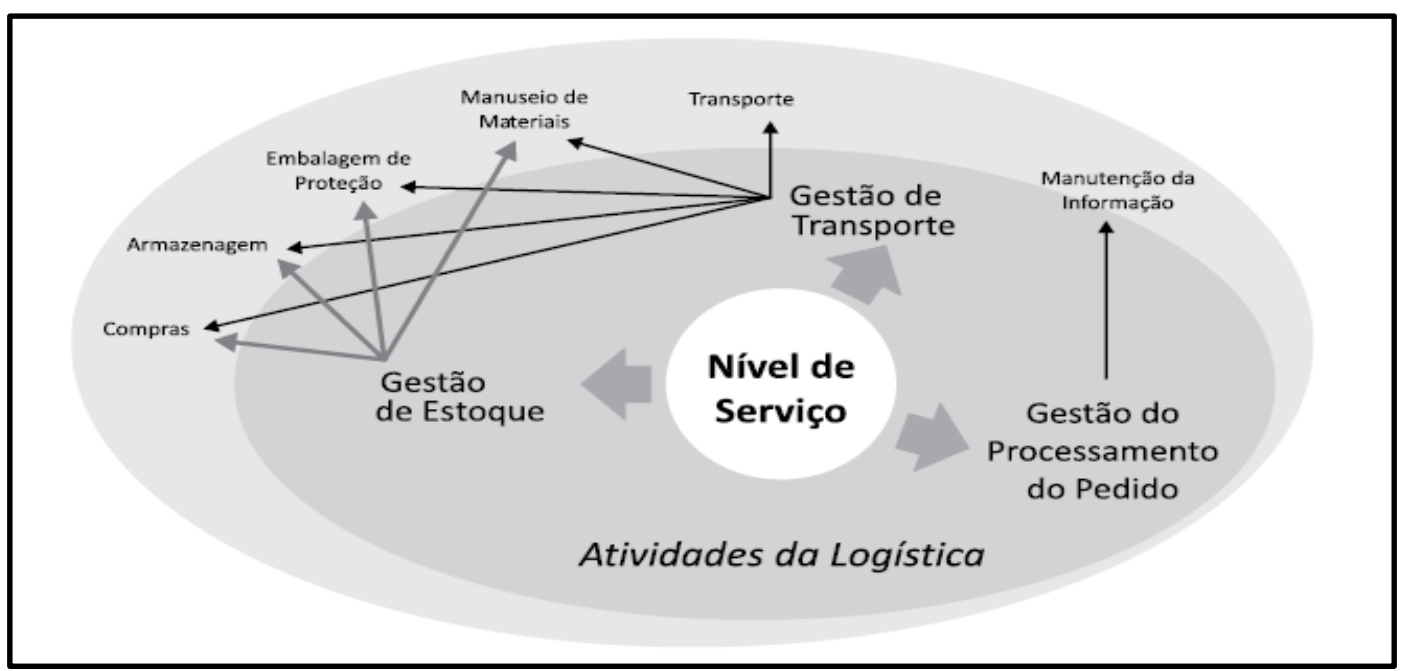
Figura 4 - Atividades da logística
Fonte: Rosa (2011).

Essa dissertação tem foco no transporte, o qual possui uma relação com o processo de distribuição física, o qual é discutido a seguir.

\section{3.}

\section{Distribuição Física}

O serviço de distribuição física pode ser definido como um pacote interrelacionado de atividades prestadas por um fornecedor, criando utilidade de tempo e espaço para um comprador (AZIZI et al., 2014). Ela compreende os processos de estocagem, transporte, controle, intercâmbio de dados e fluxo financeiro, os quais permitem que os produtos sejam transferidos desde o fabricante até seu consumidor final (SANTOS et al., 2012).

Santos et al. (2012) destacam que o objetivo de um sistema de distribuição física é entregar ao cliente final o produto certo, no lugar correto, no momento exato e com o nível de serviço desejado, a fim de minimizar os custos do serviço logístico. A distribuição física opera na logística de saída da empresa, ou seja, a jusante de uma cadeia de suprimentos, ligando produtores a seus clientes finais (SANTOS et al., 2012; XING e GRANT, 2006). 
As atividades que compõem o sistema de distribuição variam de acordo com a empresa, contudo Ballou (2006) identificou as seguintes atividades-chaves: serviços padronizados ao cliente, transporte, gerência de estoques e fluxos de informações e processamentos de pedido.

Enomoto (2005) e Marques (2002) afirmam que o gerenciamento da distribuição física ocorre em três níveis: estratégico, tático e operacional. No nível estratégico o gerenciamento está relacionado a decisões de longo prazo com o objetivo de definir as linhas gerais do sistema (ENOMOTO, 2005). Algumas das decisões nesse nível estão relacionadas à definição da rede logística, tentando minimizar o custo logístico mantendo o nível de serviço; decisão de utilização dos modais, com base no impacto nos serviços e nos custos e decisão da propriedade da frota (MARQUES, 2002).

Já no nível tático, Enomoto (2005) destaca a existência de um planejamento de médio e longo prazo, assegurando a maior eficiência na operação do sistema e a utilização dos recursos selecionados no nível estratégico. Ainda segundo o mesmo autor, algumas das atividades são: planejamento de transportes, seleção e contratação de transportadores e análise de frete. É nesse nível que estão incluídos os problemas de tamanho e mix de frota.

O nível operacional cuida da programação, execução e controle das atividades realizadas diariamente, como os procedimentos de armazenamento e movimentação interna dos materiais, a carga e descarga dos veículos, a emissão de documentos e a programação dos roteiros de entrega (ENOMOTO, 2005; MARQUES, 2002). Dessa forma, percebe-se que é nesse nível que são encontrados os problemas de roteirização de veículos, os quais são o foco deste trabalho. Vale ressaltar que a roteirização surge como alternativa a um esquema de distribuição mais clássico denominado de "um para um", na qual o veículo é totalmente carregado no centro de distribuição ou na fábrica e transporta a carga para outro ponto (NOVAES, 2004).

\section{4 .}

\section{Roteirização De Veículos}

O problema de roteamento de veículos (Vehicle Routing Problem - VRP) pode ser definido como um problema de desenho de rotas de entrega ótimas a partir de um ou mais depósitos para um número de cidades ou consumidores geograficamente dispersos sujeito a algumas restrições (LAPORTE, 1992). 
Laporte (2009) destaca que o clássico trabalho de Dantzig e Ramser (1959) introduziu o VRP para a comunidade acadêmica e também apresentou a primeira heurística para resolução desse tipo de problema, a qual combinava vértices ou vértices e rotas parciais a fim de construir um conjunto de rotas para os veículos.

Gendreau et al. (1996) e Laporte (1992) descrevem matematicamente o problema como seja $G=(V, A)$ um grafo, onde $V=\left\{v_{1}, v_{2}, \ldots, v_{n}\right\}$ é um conjunto de vértices ou cidades e $A=\left\{\left(v_{i}, v_{j}\right): i \neq j, v_{i}, v_{j} \in V\right\}$ é um conjunto de arcos. Ainda segundo os mesmos autores, a matriz $C=\left(c_{i j}\right)$ é definida em $A$ e em alguns contextos representa o custo, distâncias ou o tempo da viagem.

O VRP consiste em desenhar um conjunto de rotas de custo mínimo, no qual cada cidade é visitada exatamente uma vez por um veículo e todas as rotas começam e terminam no depósito (LAPORTE, 1992). As restrições mais comuns, segundo Laporte (1992) e Gendreau et al. (1996) são as seguintes:

- Restrições de capacidade: Cada cidade possui uma demanda própria, sendo que a demanda total de todos os vértices não pode exceder a capacidade do caminhão, além da soma dos pesos de qualquer rota do veículo não podem exceder a sua capacidade;

- Restrições de duração: O tempo total de cada rota não pode exceder o valor de uma dada constante;

- Restrições de janela de tempo: Cada cidade deve ser visitada dentro de um intervalo de tempo;

- Restrições de precedência: Dado um par de cidade, a cidade $i$ deve ser visitada antes da cidade $j$.

A formulação matemática do problema, conforme proposta por Fisher e Jaikumar (1979) é apresentada abaixo.

Parâmetros:

$K=$ Número de veículos;

$n=$ Número de cidades no qual a entrega deve ser feita. As cidades são indexadas de 1 até $n$ e o índice 0 representa o depósito central;

$b_{k}=$ Capacidade do veículo $k$;

$a_{i}=$ Demanda para a cidade $i$

$c_{i j}=$ Custo da viagem direta da cidade $i$ para a cidade $j$.

Variáveis:

$y_{i k}=1$, se o pedido da cidade $i$ é entregue pelo veículo $k$. 0 , caso contrário;

$x_{i j k}=1$, se o veículo $k$ viaja diretamente da cidade $i$ para a cidade $j .0$, caso contrário. 
Função objetivo:

$$
\begin{aligned}
& \operatorname{Min} \sum_{i j k} c_{i j} x_{i j k} \\
& \quad \text { Sujeito a: } \\
& \sum_{i} a_{i} y_{i k} \leq b_{k}, k=1, \ldots, K \\
& \sum_{k} y_{i k}=\left\{\begin{array}{l}
K, \\
1, \quad i=0
\end{array}\right. \\
& \sum_{i} x_{i j k}=y_{j k}, j=0, \ldots, n ; k=1, \ldots, K \\
& \sum_{j} x_{i j k}=y_{i k}, i=0, \ldots, n ; k=1, \ldots K \\
& \sum_{i j \in S \times S} x_{i j k} \leq|S|-1, S \subseteq\{1, \ldots, n\} ; 2 \leq|S| \leq n-1 ; k=1, \ldots, K \\
& x_{i j k}=0 \text { ou } 1, i=0, \ldots, n ; j=0, \ldots, n ; k=1, \ldots, K \\
& y_{i k}=0 \text { ou } 1, i=0, \ldots, n ; k=1, \ldots, K
\end{aligned}
$$

$\mathrm{Na}$ formulação apresentada, a função objetivo (2.1) visa minimizar o custo total de distribuição. As restrições (2.2) garantem que a carga designada para cada veículo está dentro da sua capacidade e as restrições (2.3) representam um problema de atribuição generalizada, garantindo que cada rota comece e termine no depósito. Se os $y_{i k}$ são fixos para satisfazer (2.2) e (2.3), então para um dado $k$, as restrições de (2.4) a (2.6) definem um problema do caixeiro viajante (TSP Traveling Salesman Problem) para os clientes alocados ao veículo $k$. As restrições (2.7) e (2.8) garantem que as variáveis de decisão são binárias.

\subsection{1.}

\section{Classificação Dos Problemas De Roteirização}

Devido à diversidade dos problemas de roteirização de veículos, Raff (1983) analisou mais de 700 trabalhos envolvendo a roteirização e a programação de veículos, a fim de categorizar e classificar os problemas existentes, além de destacar os algoritmos e metodologias mais utilizados. A classificação proposta pelo autor pode ser visualizada na Tabela 1.

Desrochers et al. (1990) ressaltam que a grande quantidade de problemas de roteamento e programação de veículos tornam difícil a escolha do melhor método de resolução para quem não tem experiência no ramo, logo, eles também propuseram uma classificação baseada em três níveis: a situação - problema real, 
o tipo de problema abstrato (modelagem das entidades em decisões, objetivos e restrições) e o algoritmo.

Tabela 1 - Características dos problemas de roteirização e programação

\begin{tabular}{|c|c|}
\hline Características & Possibilidades \\
\hline Tamanho da frota disponível & $\begin{array}{l}\text { - Um veículo; } \\
\text { - Múltiplos veículos. }\end{array}$ \\
\hline Tipo de frota disponível & $\begin{array}{l}\text { - Homogênea (único tipo de veículo); } \\
\text { - Heterogênea (múltiplos tipos de veículo); } \\
\text { - Veículos especiais. }\end{array}$ \\
\hline Garagem dos veículos & $\begin{array}{l}\text { - Único depósito; } \\
\text { - Múltiplos depósitos. }\end{array}$ \\
\hline Natureza da demanda & $\begin{array}{l}\text { - Determinística; } \\
\text { - Estocástica; } \\
\text { - Demanda parcialmente atendida. }\end{array}$ \\
\hline Localização da demanda & $\begin{array}{l}\text { - Nos nós; } \\
\text { - Nos arcos; } \\
\text { - Mista. }\end{array}$ \\
\hline Característica da rede & $\begin{array}{l}\text { - Não-orientada; } \\
\text { - Orientada; } \\
\text { - Mista; } \\
\text { - Euclidiana. }\end{array}$ \\
\hline Restrições de capacidade dos veículos & $\begin{array}{l}\text { - Impostas (veículos com mesma } \\
\text { capacidade); } \\
\text { - Impostas (veículos com capacidades } \\
\text { diferentes); } \\
\text { - Não-impostas (capacidade ilimitada). }\end{array}$ \\
\hline Tempo máximo de rota & $\begin{array}{l}\text { - Imposto (mesmo tempo para toda rota); } \\
\text { - Imposto (diferente para rotas distintas); } \\
\text { - Não-imposto. }\end{array}$ \\
\hline Operações & $\begin{array}{l}\text { - Somente coletas; } \\
\text { - Somente entregas; } \\
\text { - Mista (entregas e coletas); } \\
\text { - Entregas parceladas. }\end{array}$ \\
\hline Custos & $\begin{array}{l}\text { - Variáveis; } \\
\text { - Fixos ou custo de aquisição dos } \\
\text { veículos; } \\
\text { - Custos comuns de transporte. }\end{array}$ \\
\hline Objetivos & $\begin{array}{l}\text { - Minimização dos custos totais de } \\
\text { roteirização; } \\
\text { - Minimização da soma dos custos fixos e } \\
\text { variáveis; } \\
\text { - Minimização do número de veículos } \\
\text { necessários; } \\
\text { - Maximização da função utilidade } \\
\text { (baseada em serviço, conveniência ou } \\
\text { prioridades do cliente). }\end{array}$ \\
\hline
\end{tabular}

Fonte: Adaptado de Raff (1983).

Apesar do nível de detalhe do trabalho de Desrochers et al. (1990) ser muito maior do que o de Raff (1983), este é mais objetivo, logo, foi a classificação utilizada na construção do trabalho. 


\subsection{2.}

\section{Roteirização De Veículos Com Estoque (IRP)}

É comum ao analisar um problema, decompô-lo em partes menores e resolvê-las separadamente a fim de encontrar uma solução, contudo, essa prática termina por gerar soluções sub-ótimas que não atendem as necessidades (BERTAZZI e SPERANZA, 2012). Em razão dos avanços tecnológicos, sistemas de informação, ferramentas para a tomada de decisão e pesquisas científicas, essa prática de decomposição está sendo deixada de lado, e cada vez mais as partes de um sistema logístico são mais integradas (ARCHETTI e SPERANZA, 2015).

Um exemplo da situação descrita acima é a utilização da prática de gerenciamento dos estoques pelo fornecedor ou VMI (vendor-managed inventory). Na política do VMI, segundo Archetti e Speranza (2015), o fornecedor monitora os níveis de estoque dos seus clientes e determina a quantidade e quando será feita a entrega, evitando a falta de produto.

Entre as principais vantagens na utilização desse tipo de prática, Coelho et al. (2012) destacam que os fornecedores economizam nos custos de produção e distribuição, pois podem coordenar, demandar e carregamentos para clientes diferentes, já os clientes, ganham por não alocarem recursos em controle e gestão de estoque, ou seja, a relação pode ser descrita como ganha/ganha.

No VMI, o fornecedor, de acordo com Coelho et al. (2012), necessita tomar três decisões importantes: quando servir o cliente, qual a quantidade a entregar e como organizar os clientes nas rotas. Ainda segundo o mesmo autor, o VMI sugere a resolução de um problema de roteirização de veículos com estoque ou IRP (Inventory - Routing Problem).

Li et al. (2011) definem o IRP como um problema que determina as decisões de reposição de estoque para os varejistas ao mesmo tempo que as rotas para os veículos que realizam essas reposições. O objetivo de um problema de IRP depende da função objetivo escolhida, podendo focar na minimização dos custos de transportes, de estoques ou em ambos os custos simultaneamente (BERTAZZI e SPERANZA, 2012).

Existem diversos tipos de problemas de IRP. Bertazzi e Speranza (2012) ressaltam algumas características como tempo de entrega, o qual pode ser contínuo, contínuo com tempo mínimo entre as entregas e discreto. O horizonte de planejamento também é uma das características mencionadas pelos autores, 
podendo ser infinito ou finito. Uma representação gráfica do problema pode ser visualizada na Figura 5.

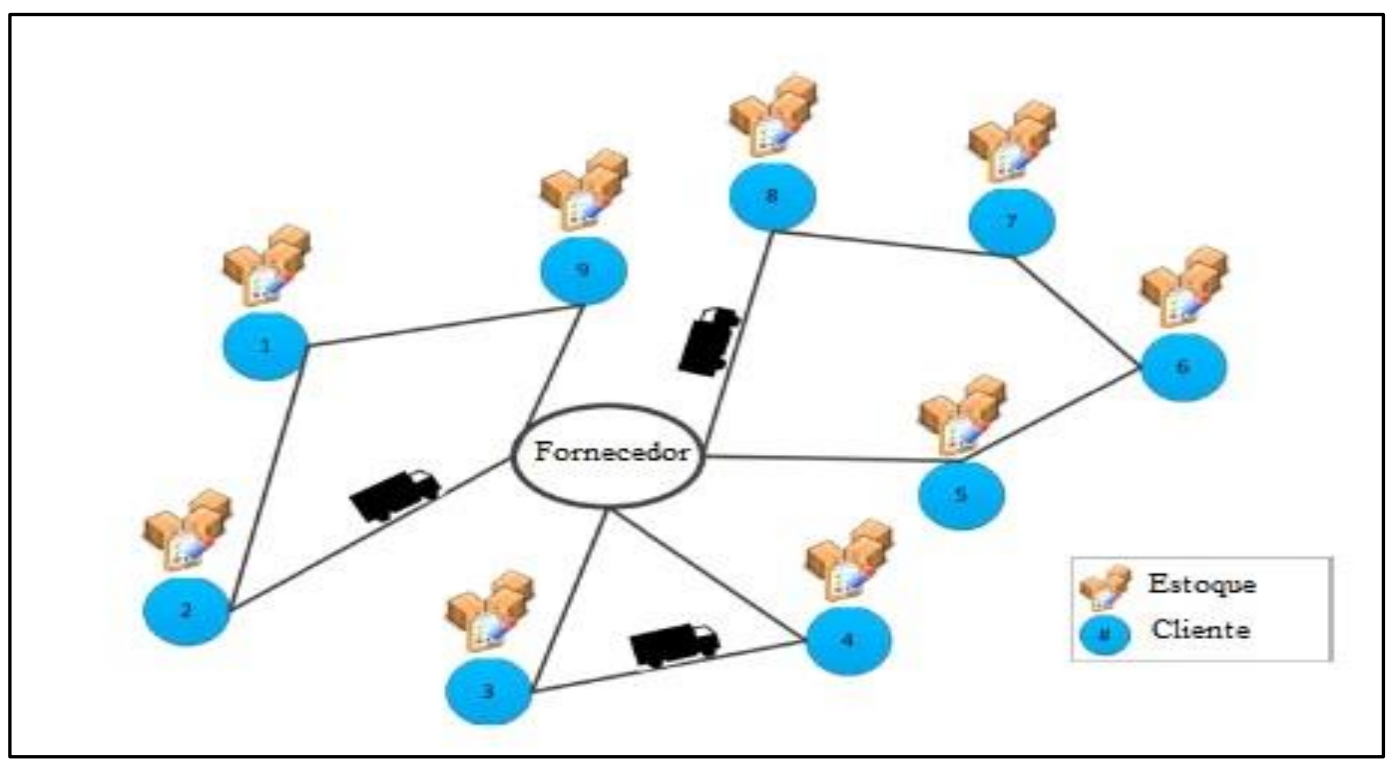

Figura 5 - Representação genérica de um IRP Fonte: Adaptado de Soysal et al. (2015).

Em relação aos estudos sobre IRP, Archetti et al. (2007) desenvolveram um modelo de programação linear inteira-mista no qual um produto deve ser entregue a vários varejistas em um determinado período de tempo, sendo que cada varejista determina um nível máximo de estoque, o qual deve ser atendido em cada entrega. O modelo em questão foi resolvido com o algoritmo branch-and-cut.

Archetti et al. (2012) desenvolveram uma heurística híbrida HAIR (Hybrid Approach to Inventory Routing), a qual combina busca tabu com a solução de problemas de programação inteira. Nesse caso, a programação inteira não apresentou problemas em resolver instâncias com 200 clientes e 6 horizontes de tempo, contudo, para instâncias maiores foi estabelecido um tempo limite e utilizada a melhor solução encontrada. A heurística HAIR apresentou um erro menor do que $1 \%$ nas mesmas instâncias, comprovando sua eficiência.

Chandra e Fisher (1994) compararam a resolução dos problemas de estoque e roteirização juntos e separados, avaliando os benefícios de coordenar as duas práticas. Gaur e Fisher (2004) estudaram o problema de roteamento de veículos com estoques periódicos, com uma frota heterogênea e com capacidade infinita de uma rede de supermercados. Com a implantação do modelo, Gaur e Fisher (2004) economizaram cerca de 4\% dos custos de distribuição.

Li et al. (2011) elaboraram um modelo de entregas parceladas de um depósito para vários varejistas, com uma frota de veículos com capacidade 
limitada, reduzindo os custos com estoque, todavia, sem aumentar os custos com transportes.

Já Soysal et al. (2015) abordaram um problema de IRP multi-período que levasse em consideração as emissões de $\mathrm{CO} 2$, o consumo de combustível, perecibilidade dos produtos e nível de serviço para uma demanda incerta. O modelo de Soysal et al. (2015) foi aplicado na distribuição de vegetais em uma cadeia de supermercado.

Além de existirem diferentes modelos e aplicações de IRP, também existem diferentes métodos de solução, como o trabalho de Guemri et al. (2016) trabalhou com uma heurística baseada no GRASP (Greedy Randomized Adaptative Search Procedure) para o problema de IRP com multi-veículos e multi-produtos. O método utilizado por Guemri et al. (2016) envolve duas fases, na qual a primeira é um procedimento aleatório guloso, o qual procura o melhor valor entre o custo de estoque e o de distribuição; já a segunda fase utiliza uma busca local, nesse caso uma Busca Tabu, para melhorar a solução encontrada na primeira fase.

O trabalho de Liu et al. (2015) focou na resolução de um problema de IRP periódico. A heurística adotada foi uma mistura de PSO (Particle Swarm Optimization) com LNS (Large Neighborhood Search), a fim de evitar que somente com a utilização da PSO, a solução ficasse presa em um ótimo local. Segundo os autores, o novo método é 10,93\% melhor do que o existente e 1,86\% melhor que uma heurística pura quando são avaliados em termos de custo médio.

Shaabani e Kamalabadi (2016) desenvolveram um algoritmo PBSA (Population-Based Simulated Annealing) para um problema de IRP com multiveículos e multi-produtos perecíveis com um ciclo de vida fixo. O algoritmo dos autores foi comparado com os métodos simulated annealing e algoritmos genéticos, mostrando a superioridade do algoritmo PBSA na resolução desse tipo de problema.

Dessa forma, pode-se perceber que existem inúmeras variações e métodos de resolução para o problema de IRP. Para o desenvolvimento do trabalho, foi considerada a variação onde existe o transbordo e o método de resolução foi a programação inteira-mista, sendo o transbordo discutido no tópico seguinte.

\subsection{3.}

\section{Roteirização De Veículos Com Estoque E Transbordo (IRPT)}


Uma das variações dos problemas de IRP consiste na existência de transbordo, originando os problemas de roteirização de veículos com estoque e transbordo ou IRPT (Inventory Routing Problem with Transshipment).

Coelho et al. (2012) destacam que o transbordo ocorre quando um cliente é abastecido com os produtos de outro cliente, sendo essa prática muito comum entre lojas pertencentes a uma mesma cadeia. $O$ transbordo pode ser utilizado como estratégia de redistribuição do estoque ou como método de atendimento a demanda que não está sendo atendida com o estoque existente no local (PATERSON et al., 2011).

O transbordo pode ser benéfico em um contexto determinístico no qual não existe falta de produtos, pois ele pode produzir uma redução na distribuição e no custo de exploração do inventário (COELHO et al., 2012). Um exemplo de transbordo pode ser visualizado na Figura 6.

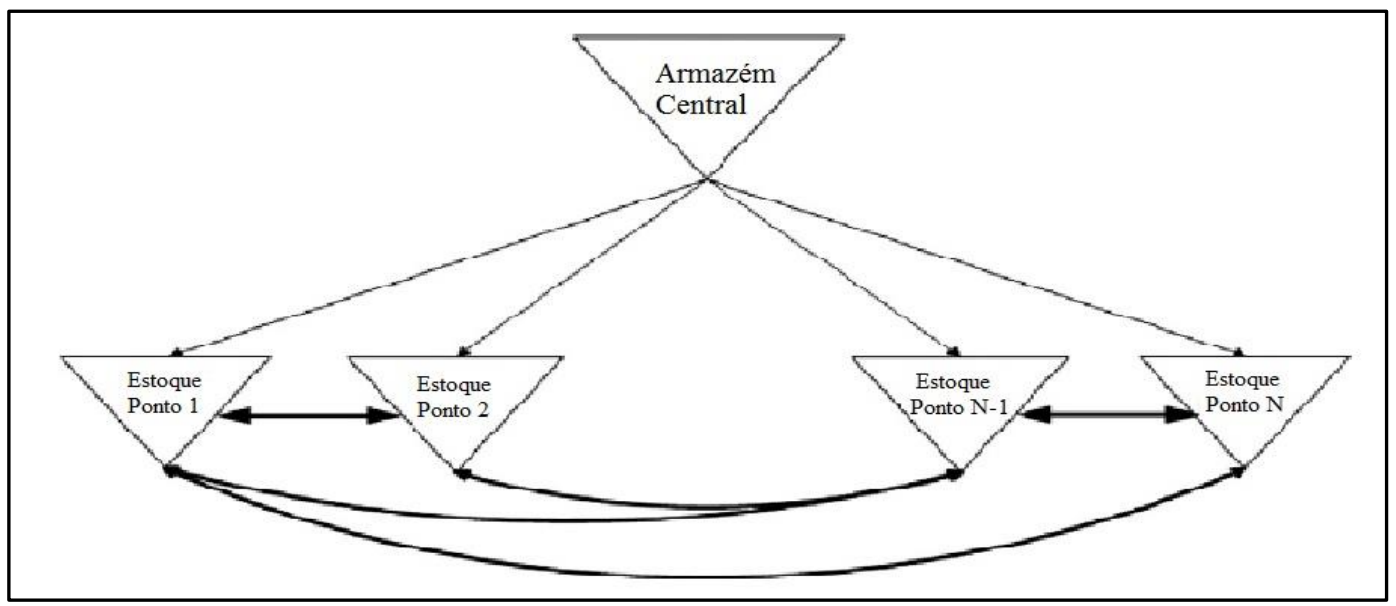

Figura 6 - Transbordo lateral

Fonte: Adaptado de Paterson et al. (2011).

Coelho et al. (2012), elaboraram um modelo de IRPT que permite o transbordo tanto de fornecedor para cliente como entre clientes. O modelo desses autores foi o principal considerado no desenvolvimento do trabalho, estando o mesmo sujeito às seguintes restrições:

- O nível de estoque de um cliente no fim de um período não pode exceder a capacidade máxima de estoque disponível;

- Estoques não podem assumir valores negativos e toda a demanda deve ser composta pelo estoque do período anterior mais as entregas do período vigente;

- O veículo do fornecedor pode executar no máximo uma rota por período de tempo, começando e terminando no depósito central;

- A capacidade do veículo não pode ser excedida. 
A formulação matemática do problema de Coelho et al. (2012) é apresentada abaixo.

Parâmetros:

$h_{i}=$ Custo unitário de estoque para cada cliente $i$;

$C_{i}=$ Capacidade de estoque de cada cliente $i$;

$d_{i}^{t}=$ Demanda de cada cliente $i$ para cada período de tempo $t$;

$r^{t}=$ Quantidade de produto disponível no fornecedor em cada período $t$;

$q_{i}^{t}=$ Quantidade de produto recebida pelo cliente $i$ no período $t$;

$Q=$ Capacidade do veículo;

$c_{i j}=$ Custo da rota no arco $(i, j)$;

$b_{i j}=$ Custo associado ao transbordo de produtos de $i$ para $j$.

Variáveis:

$x_{i j}^{t}=1$, se o cliente $j$ é visitado após o cliente $i$ na rota do veículo do fornecedor em cada período $t$, 0 caso contrário;

$w_{i j}^{t}=$ Quantidade de produto entregue de $i$ para $j$ no período $t$;

$I_{i}^{t}=$ Nível de estoque do cliente $i$ ao final do período $t$;

$v_{i}^{t}=$ Soma das entregas feitas pelo veículo no período $t$, após visitar o cliente $i$.

Função objetivo:

$\operatorname{Min} \sum_{t \in T} h_{0} I_{0}^{t}+\sum_{i \in V^{\prime}} \sum_{t \in T} h_{i} I_{i}^{t}+\sum_{i \in V} \sum_{j \in V} \sum_{t \in T} c_{i j} x_{i j}^{t}+\sum_{i \in R \cup\{0\}} \sum_{j \in V^{\prime}} \sum_{t \in T} b_{i j} w_{i j}^{t}$

Sujeito a:

$I_{0}^{t}=I_{0}^{t-1}+r^{t}-\sum_{i \in V^{\prime}} q_{i}^{t}-\sum_{i \in V^{\prime}} w_{0 i}^{t}, t \in T$

$I_{0}^{t} \geq 0, t \in T$

$I_{i}^{t}=I_{i}^{t-1}+q_{i}^{t}+\sum_{j \in R \cup\{0\}} w_{j i}^{t}-\sum_{j \in V^{\prime}} w_{i j}^{t}-d_{i}^{t}, i \in V^{\prime}, t \in T$

$I_{i}^{t} \geq 0, i \in V, t \in T$

$I_{i}^{t} \leq C_{i}, i \in V, t \in T$

$q_{i}^{t} \geq C_{i} \sum_{j \in V^{\prime}} x_{i j}^{t}-I_{i}^{t-1}, i \in V^{\prime}, t \in T$

$q_{i}^{t} \leq C_{i}-I_{i}^{t-1}, i \in V^{\prime}, t \in T$

$q_{i}^{t} \leq C_{i} \sum_{j \in V} x_{i j}^{t}, i \in V^{\prime}, t \in T$ 


$$
\begin{aligned}
& \sum_{i \in V} q_{i}^{t} \leq Q, t \in T \\
& \sum_{i \in V} x_{i j}^{t}=\sum_{i \in V} x_{j i}^{t}, j \in V, t \in T \\
& \sum_{i \in V} x_{i 0}^{t} \leq 1, t \in T \\
& v_{i}^{t}-v_{j}^{t}+Q x_{i j}^{t} \leq Q-q_{j}^{t}, i \in V^{\prime}, j \in V^{\prime}, t \in T \\
& q_{i}^{t} \leq v_{i}^{t} \leq Q, i \in V^{\prime}, t \in T \\
& v_{i}^{t}, q_{i}^{t}, w_{j i}^{t} \geq 0, i \in V^{\prime}, j \in R \cup\{0\}, t \in T \\
& x_{i j}^{t} \in\{0,1\}, i, j \in V, i \neq j, t \in T
\end{aligned}
$$

Na formulação proposta, a função objetivo (2.9), visa minimizar a soma dos custos de estoques no fornecedor e nos clientes, os custos de distribuição dos veículos do fornecedor e os custos de transbordo. As restrições (2.10) e (2.12) definem o nível de estoque no final do período do fornecedor e dos clientes, respectivamente. Já as restrições (2.11) e (2.13) garantem que o estoque não seja negativo no final do período do fornecedor e dos clientes, respectivamente.

As restrições (2.14) assegura que o estoque não exceda a capacidade do local. As restrições (2.15) a (2.17) tem relação com as quantidades entregues, garantindo que as mesmas não excedam a capacidade do local. A quantidade entregue não pode exceder a capacidade do veículo, conforme as restrições (2.18). A conservação do fluxo e a alocação de um veículo para cada rota são expressas nas restrições (2.19) e (2.20), respectivamente. As restrições (2.21) e (2.22) asseguram a eliminação das sub-rotas e as equações (2.23) e (2.24) garantem a não-negatividade e integralidade e das variáveis.

No trabalho de Shen et al. (2011), o IRPT foi abordado no transporte de óleo a partir de um único ponto de saída, o qual é responsável por abastecer diversos portos, satisfazendo suas demandas em vários períodos de tempo. Nesse modelo foi considerada uma frota heterogênea própria do local e terceirizada, bem como o transporte dutoviário e múltiplas rotas. O objetivo consiste na determinação em cada período do número de veículos utilizados, quantos serão utilizados em cada rota e a quantidade de óleo que flui pelo duto a fim de minimizar os custos logísticos totais.

O trabalho de Coelho et al. (2012) utiliza uma heurística ALNS (Adaptative Large Neighborhood Search) que manipula as rotas dos veículos enquanto a determinação das quantidades a serem entregues e o transbordo são resolvidos por um algoritmo de fluxo de redes. 
Mais aplicações de IRPT podem ser observadas em Coelho e Laporte (2013a), onde foram resolvidas, por meio do algoritmo de branch and cut, várias classes do problema de IRP, como o IRP com múltiplos veículos com frota homogênea e heterogênea e o IRP com transbordo (IRPT).

Outro problema de IRPT pode ser observado em Mirzapour Al-e-Hashem e Rekik (2014), os quais desenvolveram um modelo de IRPT com multiprodutos e multi-períodos, onde vários veículos atendem um único cliente a partir de vários fornecedores. Além disso, uma questão de logística verde foi incorporada ao modelo, levando em consideração o custo de transporte e os níveis de emissão de gás.

Apesar da grande maioria dos problemas de IRP ou IRPT serem resolvidos por meio de heurísticas, Mirzapour Al-e-Hashem e Rekik (2014), Shen et al. (2011), Archetti et al. (2007), Coelho e Laporte (2013a) e Coelho e Laporte (2013b), resolveram seus modelos de forma exata e conseguiram bons resultados. Dessa forma, pode-se perceber que a programação inteira também é uma alternativa para a resolução de problemas de IRPT, sendo esse método de solução o método utilizado no presente trabalho. 


\section{3}

\section{Metodologia Da Pesquisa}

Neste capítulo é exposta a classificação e as etapas da pesquisa com base nos conceitos apresentados por Silva e Menezes (2005). Para uma melhor compreensão, o capítulo foi dividido em dois tópicos: caracterização e delineamento da pesquisa e etapas da concepção do estudo.

\section{1.}

\section{Caracterização E Delineamento Da Pesquisa}

Neste tópico, a pesquisa será dividida quanto à sua natureza, forma de abordagem, ponto de vista dos objetivos e seus procedimentos técnicos.

\subsection{1.}

\section{Natureza Da Pesquisa}

Em relação à sua natureza, a pesquisa pode ser considerada uma pesquisa aplicada, pois tem por objetivo gerar conhecimentos para uma situação prática, visando resolver problemas de uma situação específica.

\subsection{2.}

\section{Forma De Abordagem Do Problema}

A forma de abordagem do problema é quantitativa, visto que todos os dados do problema podem ser quantificados matematicamente.

\subsection{3.}

\section{Ponto De Vista Dos Objetivos}

Quanto aos seus objetivos, a pesquisa assume caráter exploratório, pois assume a forma de pesquisa bibliográfica e estudo de caso, proporcionando maior familiaridade com o problema. 


\subsection{4.}

\section{Ponto De Vista Dos Procedimentos Técnicos}

Em relação aos procedimentos técnicos, a pesquisa é do tipo bibliográfica, pois foi desenvolvida a partir de material já publicado; experimental, visto que foram determinados um objeto de estudo e as variáveis que podem influenciá-lo; estudo de caso, em função do estudo profundo de um objeto e participante, pois houve interação entre os pesquisadores e os membros das situações investigadas.

\section{2.}

\section{Etapas Da Concepção Do Estudo}

Para o desenvolvimento desta dissertação de mestrado, o método de estudo seguiu as etapas abaixo:

- Definição do tema e do local de aplicação da pesquisa;

- Revisão da literatura acerca dos problemas de roteirização de veículos e suas variações, bem como dos métodos de solução;

- Desenvolvimento do modelo matemático do Problema de Roteirização de Veículos com Estoque e Transbordo, com base em um modelo já existente; - Implementação e resolução do modelo em menor escala no software Xpress, a fim de analisar e validar o modelo;

- Resolução do modelo com os dados reais da empresa;

- Elaboração da conclusão e das propostas de trabalhos futuros. 


\section{Modelo De Roteirização De Veículos Com Estoque E Transbordo, IRPT}

Este capítulo tem como objetivo o detalhamento do modelo matemático desenvolvido, estando dividido em cinco seções. A seção 4.1 apresenta a caracterização do problema analisado, já as seções 4.2 e 4.3 são dedicadas à formulação matemática do problema e às restrições de eliminação de subrotas. As seções 4.4 e 4.5 são responsáveis pela validação do modelo e análise de cenários, respectivamente.

\section{1.}

\section{Caracterização Do Problema}

O problema em questão possui o mesmo objetivo de um problema de IRP clássico, visto que procura determinar as rotas de reposição de estoque de um conjunto de CD's, a partir de uma fábrica que consolida a produção. Contudo, o modelo matemático desenvolvido considera a possibilidade da ocorrência de transbordo de produtos entre os CD's, ou seja, cada CD não é abastecido exclusivamente pela fábrica, podendo receber produto de outros CD's de acordo com a sua necessidade.

Outra variação do modelo é o fato de que ele trabalha com múltiplos veículos e múltiplos produtos, diferentemente do problema original de IRP e IRPT. Como solução, espera-se obter um conjunto de rotas que minimizem os custos de distribuição associados aos custos de estocagem dos produtos nos CD's.

\section{2.}

\section{Formulação Do Problema}

O problema apresentado nessa dissertação é considerado um Problema de Roteirização de Veículos com Estoque, levando em consideração a existência de transbordo e múltiplos veículos e produtos (Multi-Product Multi-Vehicle Inventory Routing Problem with Transshipment-MMIRPT. 
O problema pode ser definido como segue: dado um grafo definido como $G=(V, A)$, onde o conjunto de vértices $V$ é composto por $V^{d}=\{d\}$, o qual representa a Fábrica, e por $V^{c}=\{1, \ldots, c\}$, representando os Centros de Distribuição, ou seja, $V=V^{d} \cup V^{c}$. O conjunto de $\operatorname{arcos} A$ é definido como $A=$ $\{(i, j) \mid i, j \in V, i \neq j\}$. O conjunto dos veículos é expresso por $N=\{1, \ldots, n\}$ e o conjunto dos produtos por $P=\{1, \ldots, p\}$. Por se tratar de um problema de IRP, o qual por natureza é composto por múltiplos períodos, tem-se o conjunto dos períodos representado por $T=\{1, \ldots, t\}$, o qual define o tamanho do horizonte de planejamento.

A capacidade de armazenagem de cada nó $i$ é expressa por $C A_{i}$. A demanda de cada produto $p$ para cada CD $c$ em cada período de tempo $t$ é representada por $D C_{c t p}$ e o tempo de atendimento de cada local é conhecido como $T A$. O tempo de deslocamento entre os locais $i$ e $j$ é expresso por $T D_{i j}$ e $T C$ é o tempo de ciclo do modelo. A fábrica possui uma produção de cada produto $p$ em cada período $t$ expressa por $P F_{t p} . E I_{i p}$ representa o estoque inicial do local $i$ em cada período $t$.

Os produtos da empresa quando saem da fábrica possuem um custo $C S$, no qual já está inclusa a tributação (impostos) que o produto recebe. O custo de transporte entre o nó $i$ e o nó $j$ é expresso por $C_{i j}$. A empresa possui uma quantidade fixa $k$ de veículos e os mesmos possuem capacidades iguais determinadas por $q$.

Em função do problema lidar com custos de estoque, considera-se uma taxa de juros $T J$, a qual incide sobre os produtos deixados em estoque pelo fato do estoque ser considerado capital parado.

Cada veículo inicia e termina sua rota na fábrica, devendo cumprir as seguintes premissas:

- A quantidade de carga transportada por cada veículo não deve exceder a sua capacidade;

- O tempo de percurso do veículo não deve ultrapassar o tempo de ciclo estipulado para o veículo;

- Cada veículo atende pelo menos um CD;

- Todo veículo deve chegar e sair de cada CD.

Além das restrições dos veículos, considera-se que a fábrica possui capacidade ilimitada para atender a demanda de todos os centros de distribuição durante o horizonte de planejamento estipulado e que os níveis de estoque não podem ser negativos. O produto só pode sair da fábrica se foi produzido ou está em estoque no mesmo período de tempo. O tempo de recebimento dos produtos nos CD's não foi considerado devido ao fato de ter uma representação muito 
pequena em relação ao tempo da rota, além do que na configuração atual da empresa esse aspecto também não é levado em consideração.

O problema possui as seguintes variáveis de decisão:

$x_{i j n t}=1$, se o arco $i, j$ é utilizado pelo veículo $n$ no período $t, 0$ caso contrário;

$y_{n t}=1$, se o veículo $n$ é utilizado no período $t, 0$ caso contrário;

$E_{i, t p}=$ Nível de estoque do produto $p$, no período $t$ no local $i$;

$Q_{d c t n p}=$ Quantidade de produto $p$ transportado pelo veículo $n$, no período $t$, da fábrica $d$ para o $\mathrm{CD} c$;

$W_{\text {c cct } n p}=$ Quantidade de produto $p$ transportado pelo veículo $n$, no período $t$, do CD $c$ para o CD $c c$.

A fim de facilitar a compreensão, os elementos que compõem o modelo matemático estão expressos nas Tabelas 2 , 3 e 4, representando os conjuntos e índices, os parâmetros e as variáveis do modelo, respectivamente.

Tabela 2 - Conjuntos e índices

\begin{tabular}{ll}
\hline Conjuntos & Índices \\
\hline Nó $(\boldsymbol{V})$ & $i, j$ \\
Fábrica $\left(\boldsymbol{V}^{\boldsymbol{d}}\right)$ & $d$ \\
$\mathrm{CD}\left(\boldsymbol{V}^{\boldsymbol{c}}\right)$ & $c, c c$ \\
Veículo $(\boldsymbol{N})$ & $n$ \\
Período $(\boldsymbol{T})$ & $t$ \\
Produto $(\boldsymbol{P})$ & $p$ \\
\hline \multicolumn{2}{c}{ Fonte: Autora (2017). }
\end{tabular}

Tabela 3 - Parâmetros

\begin{tabular}{lll}
\hline Parâmetros & Descrição & Unidade \\
\hline$k$ & Quantidade de veículos & Veículos \\
$q$ & Capacidade do veículo & Unidades \\
$D C_{c t p}$ & Demanda de cada produto $p$ para o CD $c$ no período $t$ & Unidades \\
$P F_{t p}$ & Produção da fábrica do produto $p$ no período $t$ & Unidades \\
$E I_{i p}$ & Estoque inicial do produto $p$ no local $i$ & Unidades \\
$C A_{i}$ & Capacidade de armazenagem do local $i$ & Unidades \\
$T D_{i j}$ & Tempo de deslocamento no arco $(i, j)$ & Dias \\
$T C$ & Tempo de ciclo do veículo & Dias \\
$T A$ & Tempo de atendimento & Dias \\
$C_{i j}$ & Custo de transporte no arco $(i, j)$ & $\mathrm{R} \$$ \\
$C S$ & Custo de saída da fábrica & $\mathrm{R} \$$ \\
$T J$ & Taxa de juros & - \\
\hline
\end{tabular}

Fonte: Autora (2017).

Tabela 4 - Variáveis

\begin{tabular}{llll}
\hline Variáveis & Descrição & Unidade & Domínio \\
\hline$x_{i j n t}$ & $\begin{array}{l}\text { Decisão se o arco }(i, j) \text { é utilizado pelo veículo } n \\
\text { no período } t\end{array}$ & - & $\{0,1\}$
\end{tabular}




\begin{tabular}{llll}
$y_{n t}$ & Decisão se o veículo $n$ é utilizado no período $t$ & - & $\{0,1\}$ \\
$E_{i t p}$ & $\begin{array}{l}\text { Nível de estoque do produto } p \text {, no período } t \text { no } \\
\text { local } i\end{array}$ & Unidades & $\mathbb{R}_{+}$ \\
$Q_{d c t n p}$ & $\begin{array}{l}\text { Quantidade de produto } p \text { transportado pelo veículo } \\
n, \text { no período } t, \text { da fábrica } d \text { para o CD } c\end{array}$ & Unidades & $\mathbb{R}_{+}$ \\
$W_{c \text { cctn } p}$ & $\begin{array}{l}\text { Quantidade de produto } p \text { transportado pelo veículo } \\
n, \text { no período } t, \text { do CD } c \text { para o CD } c c\end{array}$ & Unidades & $\mathbb{R}_{+}$ \\
\hline
\end{tabular}
Fonte: Autora (2017).

Baseado na notação apresentada, o problema de MMIRPT é formulado conforme as equações abaixo:

Função objetivo:

$$
\text { Minimizar } \sum_{i \in V} \sum_{j \in V} \sum_{n \in N} \sum_{t \in T} C_{i j} \cdot x_{i j n t}+\sum_{i \in V^{c}} \sum_{t \in T} \sum_{p \in P} E_{i t p} \cdot C S \cdot T J
$$

Sujeito a:

$$
\begin{aligned}
& Q_{d c t n p} \leq x_{d c n t} \cdot C A_{c}, \forall d \in V^{d}, \forall c \in V^{c}, \forall t \in T, \forall n \in N, \forall p \in P \\
& W_{c c c t n p} \leq x_{c c c n t} \cdot C A_{c c}, \forall c, c c \in V^{c}, c \neq c c, \forall t \in T, \forall n \in N, \forall p \in P \\
& \sum_{c \in V^{c}} x_{d c n t}=y_{n t}, \forall d \in V^{d}, \forall t \in T, \forall n \in N \\
& \sum_{c \in V^{c}} x_{c d n t}=y_{n t}, \forall d \in V^{d}, \forall n \in N, \forall t \in T \\
& \sum_{i \in V} x_{i c n t}-\sum_{j \in V} x_{c j n t}=0, \forall c \in V^{c}, \forall n \in N, \forall t \in T \\
& E_{d t-1 p}+P F_{t p}=E_{d t p}+\sum_{c \in V^{c}} \sum_{n \in N} Q_{d c t n p}, \forall d \in V^{d}, \forall t \in T, t>1, \forall p \in P \\
& E I_{d p}+P F_{t p}=E_{d t p}+\sum_{c \in V^{c}} \sum_{n \in N} Q_{d c t n p}, \forall d \in V^{d}, \forall t \in T, t=1, \forall p \in P \\
& E_{c t-1 p}+\sum_{d \in V^{d}} \sum_{n \in N} Q_{d c t n p}+\sum_{c c \in V^{c}} \sum_{n \in N} W_{c c c t n p}=E_{c t p}+\sum_{c c \in V^{c}} \sum_{n \in N} W_{c c c t n p}+D C_{c t p}, \forall c \in V^{c}, \forall t \in T, t>1, \forall p \in P \\
& E I_{c p}+\sum_{d \in V^{d}} \sum_{n \in N} Q_{d c t n p}+\sum_{c c \in V^{c}} \sum_{n \in N} W_{c c c t n p}=E_{c t p}+\sum_{c c \in V^{c}} \sum_{n \in N} W_{c c c t n p}+D C_{c t p}, \forall c \in V^{c}, \forall t \in T, t=1, \forall p \in P \\
& \sum_{i \in V} \sum_{j \in V} T D_{i j} \cdot x_{i j n t}+\left(\sum_{i \in V} \sum_{j \in V} x_{i j n t}-y_{n t}\right) \cdot T A \leq T C \cdot y_{n t}, \forall n \in N, \forall t \in T \\
& \sum_{n \in N} y_{n t} \leq k, \forall t \in T \\
& \sum_{d \in V^{d}} \sum_{c \in V^{c}} \sum_{p \in P} Q_{d c n t p}+\sum_{c \in V^{c}} \sum_{c c \in V^{c}} \sum_{p \in P} W_{c c c n t p} \leq q \cdot y_{n t}, c \neq c c, \forall n \in N, \forall t \in T \\
& \sum_{p \in P} E_{c t p} \leq C A_{c}, \forall c \in V^{c}, \forall t \in T \\
& \sum_{i \in S} \sum_{j \in S} x_{i j n t} \leq|S|-1, \forall S \subset V, 2 \leq|S| \leq|V|-2, \forall n \in N, \forall t \in T \\
& x_{i j n t} \in\{0,1\}, \forall i \in V, \forall j \in V, i \neq j, \forall n \in N, \forall t \in T
\end{aligned}
$$




$$
\begin{aligned}
& y_{n t} \in\{0,1\}, \forall n \in N, \forall t \in T \\
& E_{i t p} \geq 0, \forall i \in V, \forall t \in T, \forall p \in P \\
& Q_{d c t n p}, W_{c c c t n p} \geq 0, \forall d \in V^{d}, \forall c \in V^{c}, \forall c c \in V^{c}, c \neq c c, \forall t \in T, \forall n \in N, \forall p \in P
\end{aligned}
$$

As restrições (4.7), (4.9), (4.13) e (4.14) foram adaptadas do modelo proposto por Coelho et al. (2012). Já as equações (4.4), (4.5) e (4.12) foram adaptadas do modelo de Mirzapour Al-e-Hashem e Rekik (2014). A função objetivo (4.1) e as restrições (4.2) e (4.6) foram apresentadas de maneira similar nos dois trabalhos citados anteriormente, contudo, sofreram alterações para 0 modelo em questão. As restrições (4.3), (4.8), (4.10) e (4.11) foram elaboradas especificamente para o estudo de caso desenvolvido. A restrição (4.15) foi adaptada do modelo de Laporte (1986).

A equação (4.1) representa a função objetivo, que compreende a minimização do custo total, o qual é composto pelo custo de distribuição somado ao custo de oportunidade de se manter estoque. As restrições (4.2) garantem que só existirá transporte da fábrica para o $C D$, se existir uma rota da fábrica para 0 CD no mesmo período de tempo. As restrições (4.3) são similares às restrições (4.2), porém é aplicada para o transporte de produto entre os CD's. As restrições (4.4) e (4.5) garantem que todo veículo deve sair e chegar à fábrica, respectivamente. As restrições (4.6) asseguram a conservação de fluxo, ou seja, a continuidade de um veículo na rota. As restrições (4.7) garantem a conservação no fluxo de estoque da fábrica, sendo que o estoque do período anterior somado à produção da fábrica no período, deve ser igual ao estoque do período mais toda a carga que sai da fábrica. As restrições (4.9) asseguram a conservação de estoque nos CD's, onde o estoque do período anterior mais a quantidade de produto recebida da fábrica e de outros CD's, deve ser igual ao estoque do período mais a quantidade de carga que sai do $C D$, somados à demanda de cada $C D$. As restrições (4.8) e (4.10) são similares às duas restrições anteriores, contudo levam em consideração o fluxo de estoque inicial na fábrica e nos CD's, respectivamente. As restrições (4.11) garantem que o tempo gasto pelo veículo não exceda seu tempo de ciclo estabelecido. As restrições (4.12) asseguram que o total de veículos utilizados não exceda a quantidade disponível. As restrições (4.13) garantem que a quantidade de carga transportada da fábrica para o CD e entre CD's não exceda a capacidade do veículo utilizado. As restrições (4.14) garantem que a capacidade do CD não seja excedida e as restrições (4.15) asseguram a eliminação de subrotas. Finalmente, as restrições (4.16) e (4.17) certificam a 
integralidade das variáveis, as restrições (4.18) e (4.19) asseguram a nãonegatividade das respectivas variáveis.

\section{3.}

Restrições De Eliminação De Subrotas

As restrições (4.15) são conhecidas como SEC's (Subtour Elimination Constraints) e garantem que sejam eliminadas as subrotas geradas pelo modelo.

Drexl (2013) ressalta a variedade de SEC's existentes e afirma que para alguns tipos o número de restrições pode ser exponencial no tamanho da instância considerada para o problema.

Uma aplicação da utilização de SEC's pode ser observada em Feiring (1986), o qual utilizou as subrotas criadas pelo modelo para criar distritos de vendas alocados a um vendedor. Já Laporte (1986) mostrou como uma classe de SEC's do problema do caixeiro viajante pode ser generalizada para problemas com diferentes características, como a roteirização de veículos capacitados (CVRP - Capacitaded Vehicle Routing Problem) e o problema de roteirizaçãolocalização de um único depósito (The Single Depot Location-Routing Problem).

Pferschy e Staněk (2016) também trabalham com as subrotas do TSP, todavia, eles utilizam somente soluções inteiras sem passar pela abordagem tradicional com soluções fracionárias.

Laporte (1986) derivou sua SEC do trabalho de Dantzig, Fulkerson e Johnson (1954), os quais, segundo Smith, Srinivasan e Thompson (1977), utilizam a relaxação do problema de alocação (AP - Assignment Problem) do TSP e eliminam as subrotas do AP resultante por meio da condução dos custos dos veículos do AP para longe dos seus verdadeiros custos, levando eles a serem números muito grandes positivos ou negativos.

As SEC's desta dissertação são derivadas do problema de TSP. Segundo Pataki (2003), esses tipos de restrições possuem como desvantagem o seu tempo exponencial para encontrar uma solução. Todavia, essa desvantagem é compensada pelo fato de que nem todas as inequações de subrota precisam estar na formulação desde o início. Ainda de acordo com o mesmo autor, elas são geradas de acordo com a necessidade por meio de um algoritmo de separação, o qual começa com a formulação básica do problema e em seguida gera inequações de subrotas que são violadas pela solução de programação linear encontrada, sendo que esse algoritmo pode ser baseado em técnicas de fluxos de rede. 
Um pseudocódigo do funcionamento das restrições do TSP pode ser observado na Figura 7.

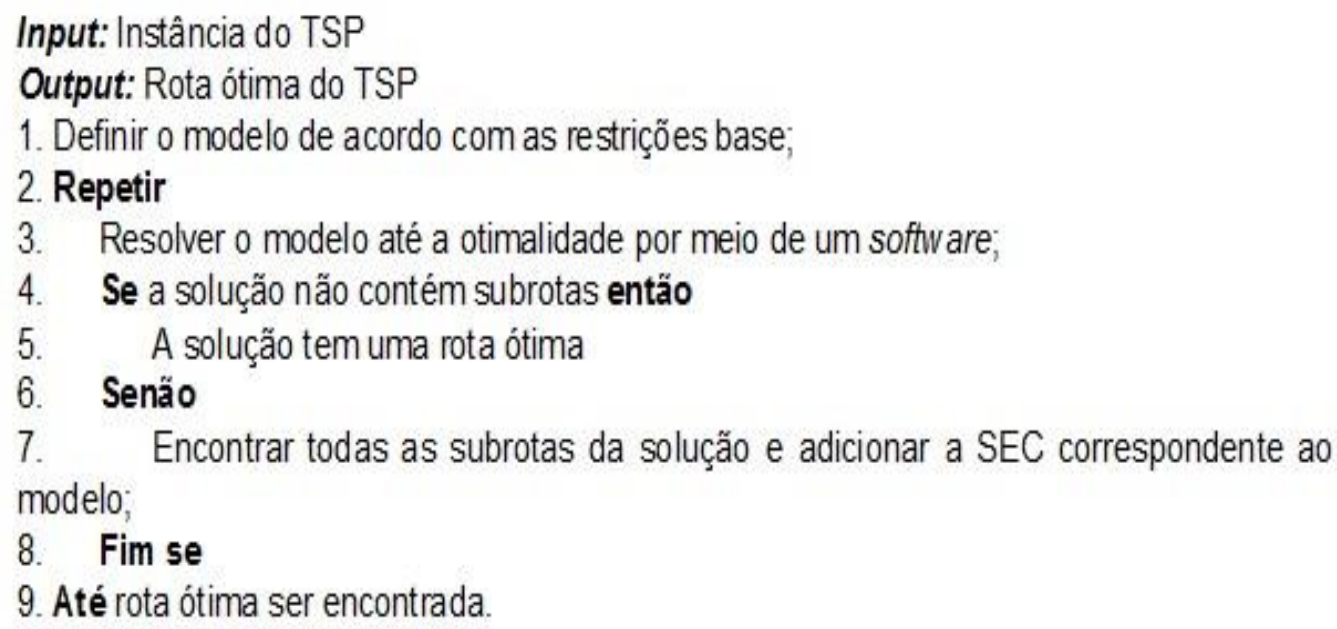

9. Até rota ótima ser encontrada.

Figura 7 - Pseudocódigo do algoritmo TSP

Fonte: Adaptado de Pferschy e Staněk (2016).

Em relação as SEC's utilizadas em problemas de IRP, Mirzapour Al-eHashem e Rekik (2014) utilizam um conjunto de inequações que garantem que a rota começa no depósito (Nó 0) e termina na planta de montagem. Já Coelho et al. (2012), criam uma nova variável $v_{i}^{t}$, a qual é a soma das entregas feitas pelo veículo no período após visitar o cliente $i$.

No modelo de Coelho et al. (2012), as SEC's utilizam a capacidade de carga do veículo para garantir que não sejam formadas subrotas. Nesse trabalho, as SEC's são representadas pelas inequações (2.21) e (2.22) já mostradas anteriormente.

Em Guemri et al. (2016), os autores não criam novas variáveis para as SEC's, sendo que para eles o somatório em todos os clientes de todas as arestas em cada período de tempo e em cada veículo deve ser menor ou igual do que o somatório da diferença entre se o cliente é ou não visitado pelo veículo no período de tempo.

\section{4.}

\section{Validação Do Modelo}

Com o objetivo de validar o modelo proposto (MMIRPT), foram realizados 2 testes. Todos os testes foram realizados com 9 nós (Fábrica + 8 CD's), diferindo apenas nos períodos de tempo. O Teste 1 foi realizado com 4 famílias de produtos e 2 períodos de tempo e o Teste 2 considerou as mesmas 4 famílias, todavia, com 4 períodos de tempo. 
Em todos os testes foi considerada uma frota reduzida da empresa, composta de 15 veículos com capacidade para 1.200 .000 caixas de produtos, bem como a produção na fábrica ser infinita. Além disso, considerou-se um tempo de ciclo igual a 7 dias, sendo que todos os dados são reais e representam as demandas de uma empresa produtora e distribuidora de cigarros localizada no Rio de Janeiro. Na Tabela 5, estão expressos os valores da demanda de 4 famílias de produtos, os quais foram obtidos por meio da soma da demanda das 12 famílias divididas em 3 grupos de produtos.

Tabela 5 - Demanda de cada família de produto por CD no período de 7 dias (5.000 unidades)

\begin{tabular}{lcccc}
\hline Local/Produto & $\mathbf{1}$ & $\mathbf{2}$ & $\mathbf{3}$ & $\mathbf{4}$ \\
\hline CD 1 & 92,43 & 75,33 & 21,26 & 2,79 \\
CD 2 & 106,47 & 86,78 & 24,50 & 3,21 \\
CD 3 & 27,59 & 22,49 & 6,35 & 0,84 \\
CD 4 & 64,83 & 52,84 & 14,92 & 1,96 \\
CD 5 & 264,71 & 215,76 & 60,90 & 7,99 \\
CD 6 & 32,22 & 26,26 & 7,42 & 0,98 \\
CD 7 & 235,03 & 191,57 & 54,07 & 7,09 \\
CD 8 & 39,97 & 32,58 & 9,20 & 1,21 \\
\hline \multicolumn{5}{c}{ Fonte: Autora (2017). }
\end{tabular}

Todos os testes foram realizados, de maneira exata, no software Xpress IVE 64 bits (versão 7.9), e em um computador Intel Core i5 2,67 Ghz e 4 GB de memória RAM. Devido à alta complexidade do modelo foi estabelecido deveria rodar por 100.000 segundos e apresentar a melhor solução ao final desse período, a fim de evitar que o modelo levasse longas horas para encontrar um resultado ótimo.

No Teste 1 foram geradas 8.128 restrições e 9.972 variáveis, sendo que a primeira solução foi gerada com 3,3 segundos com um GAP de $81,57 \%$. O modelo foi rodado por aproximadamente 100.000 segundos e no instante 14.824 segundos foi encontrada a melhor solução com GAP de 10,69\%. Na Figura 8 é possível observar a distribuição das soluções ao longo do tempo. 


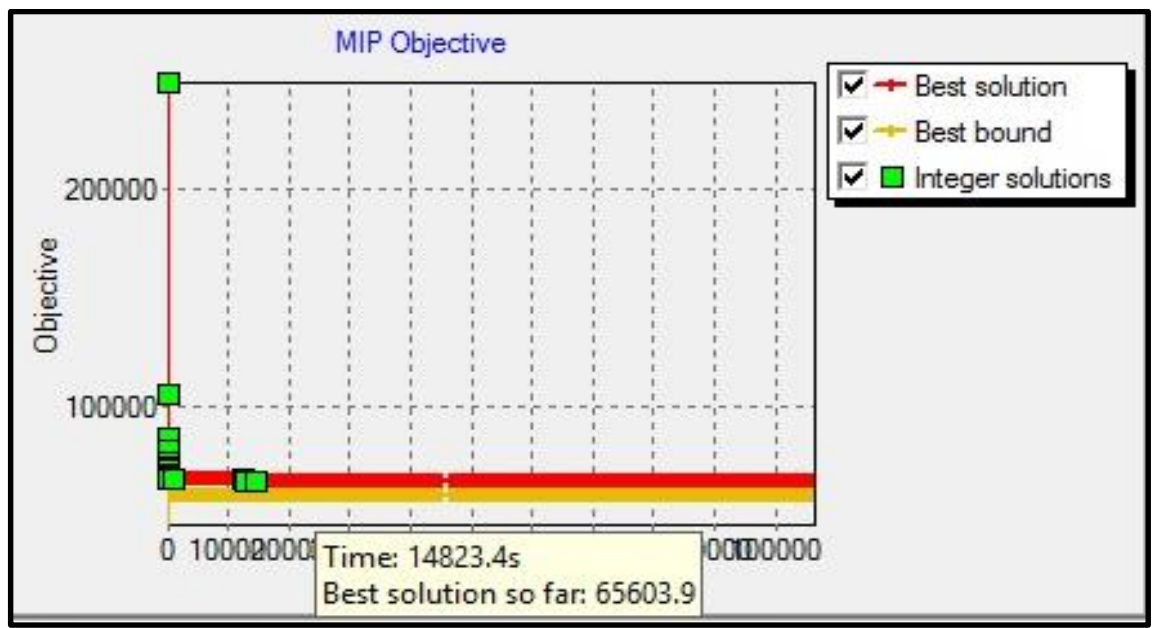

Figura 8 - Gráfico das soluções do teste 1 Fonte: Autora (2017).

A melhor solução encontrada, em relação ao best bound, tem o valor de custo igual a $R \$ 65.603,90$ e utiliza 11 veículos no primeiro período e 6 no segundo período, mostrando que sua frota, atualmente de 40 veículos, estaria superdimensionada. Todos os veículos respeitaram o tempo de ciclo de 7 dias, sendo que o máximo de dias utilizados foram 4. Além disso, todas as restrições de capacidade e roteamento foram respeitadas. Em relação ao estoque, foram formados nos CD's 2, 4, 5, 6, 7, 8 e 9 e somente no período 1, conforme ilustrado na Figura 9.

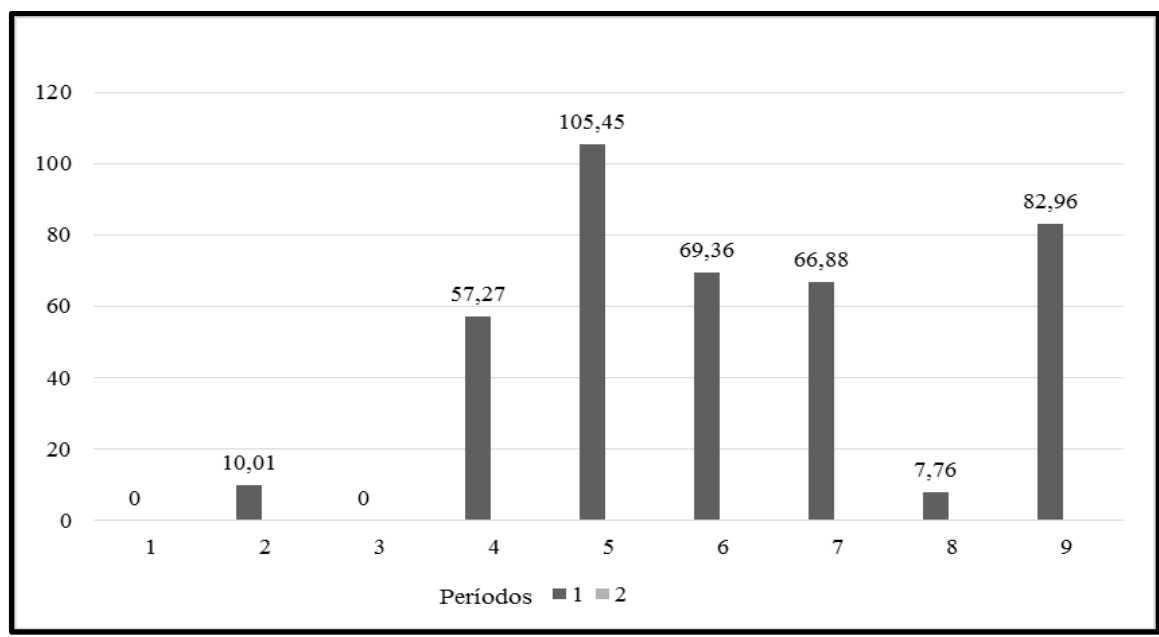

Figura 9 - Nível de estoque nos CD's no teste 1 Fonte: Autora (2017).

As rotas geradas no Teste 1 podem ser visualizadas na Tabela 6 .

Tabela 6 - Rotas geradas no teste 1

\begin{tabular}{ccc}
\hline Rotas & Veículo & Período de Tempo \\
\hline $1-2-1$ & 1 & 1 \\
$1-5-1$ & 3 & 1 \\
$1-3-1$ & 4 & 1
\end{tabular}




\begin{tabular}{ccc}
$1-8-7-6-1$ & 5 & 1 \\
$1-6-1$ & 6 & 1 \\
$1-6-1$ & 7 & 1 \\
$1-8-1$ & 8 & 1 \\
$1-7-1$ & 9 & 1 \\
$1-9-1$ & 10 & 1 \\
$1-8-4-1$ & 12 & 1 \\
$1-8-1$ & 13 & 1 \\
$1-6-1$ & 1 & 2 \\
$1-3-1$ & 3 & 2 \\
$1-6-1$ & 8 & 2 \\
$1-2-5-1$ & 10 & 2 \\
$1-8-1$ & 11 & 2 \\
$1-8-1$ & 14 & 2 \\
\hline
\end{tabular}

Fonte: Autora (2017).

Dentre as 17 rotas geradas pelo modelo, apenas 3 rotas envolveram mais de um CD, sendo esse valor correspondente a $17,65 \%$ do total de rotas. Dentre as rotas com roteiro, somente uma apresentou transbordo, a qual foi a rota $1-8$ - 7 - 6 - 1. Essa rota possui um custo total de $R \$ 4.705,35$ e o transbordo ocorre entre os pontos 7 (CD 6) e 6 (CD 5). Como no modelo não existe uma variável que indique somente a quantidade de carga proveniente do transbordo não é possível calcular o custo de estoque somente da carga do transbordo, contudo, como não existe custo de estoque entre os CD's, esse custo está presente somente na saída do produto da fábrica.

Apesar do modelo não permitir o cálculo do custo de estoque somente da carga do transbordo, por meio da variável $W$ é possível saber a quantidade de carga que vai de um CD para outro, e, dessa forma, foi observado um aumento de carga entre os pontos 7 e 6 , evidenciando a existência do transbordo. No ponto 7, o veículo chegou com 32,48 caixas no veículo, todavia, no ponto 6 ela chegou com 138,72 caixas, mostrando que houve carregamento de caixas no ponto 6 , evidenciando o transbordo.

Como a tributação do tabaco é muito alta (em torno de 66\%) em cima do custo de saída do produto da fábrica, o qual é baseado nesses impostos, foi feito mais um teste para verificar o quanto essa tributação impactava nas rotas do modelo. Dessa forma, o modelo foi rodado novamente, porém com um custo de saída da fábrica mais baixo (em torno de 9,78\%) do que o original.

Nessa nova rodada, o valor da função objetivo foi menor do que o encontrado no teste 1 , bem como o valor do GAP. Além disso, foram geradas duas rotas com transbordos, porém a quantidade de veículos utilizados no total e por período permaneceu inalterada. 
Dessa forma, observa-se que esse alto custo de saída do produto da fábrica, aliado ao fato dos custos de estoque na fábrica e nos CD's não terem sido considerados, geram menos rotas de transbordo nesse caso específico.

Em relação ao teste 2, foram geradas 16.256 restrições e 19.944 variáveis. A primeira solução foi gerada no instante 3,1 segundos, com um GAP de $80,99 \%$. Assim como no teste anterior, o modelo foi rodado por 100.000 segundos, gerando a melhor solução no instante 5.590 segundos, a qual possui um GAP de $8,62 \%$. A distribuição das soluções ao longo do tempo pode ser observada na Figura 10.



Figura 10 - Gráfico das soluções do teste 2 Fonte: Autora (2017).

A melhor solução obteve um valor de $R \$ 126.535,00$ na função objetivo, sendo que foram utilizados 12 veículos no primeiro período, 7 no segundo, 8 no terceiro e 5 no quarto, totalizando 32 veículos nos 4 períodos. Em função do aumento do número de períodos, os estoques foram mais distribuídos ao longo dos períodos de tempo, conforme ilustrado na Figura 11.

Assim como no teste 1 , no teste 2 também se observou que todas as restrições de capacidade dos locais e dos veículos foram respeitadas, bem como as restrições de roteamento, não sendo formadas subrotas pelo modelo. As rotas geradas pelo modelo no teste 2 estão na Tabela 7. 


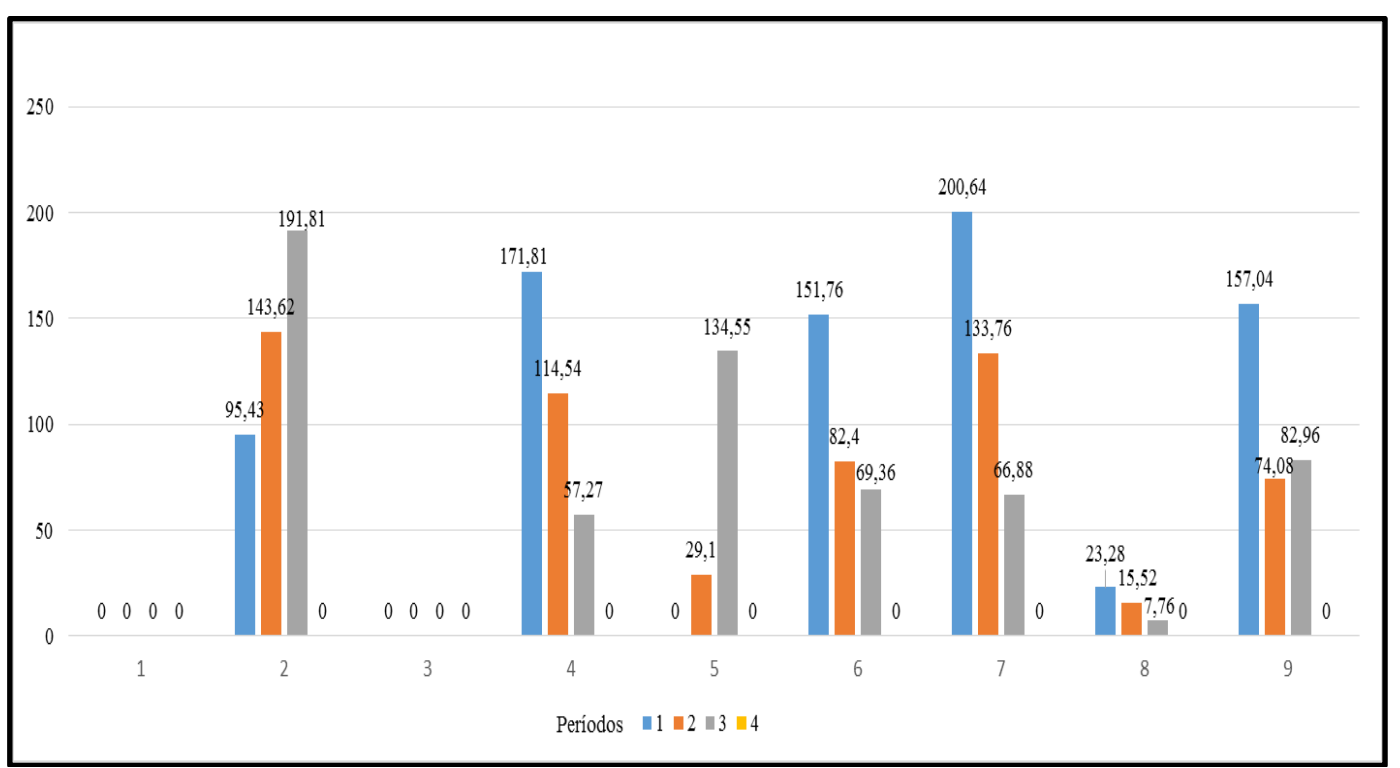

Figura 11 - Nível de estoque nos CD's no teste 2 Fonte: Autora (2017).

Tabela 7 - Rotas geradas no teste 2

\begin{tabular}{|c|c|c|}
\hline Rotas & Veículo & Período de Tempo \\
\hline $1-8-2-1$ & $\overline{1}$ & 7 \\
\hline $1-9-1$ & 3 & 1 \\
\hline $1-5-1$ & 4 & 1 \\
\hline $1-8-1$ & 5 & 1 \\
\hline $1-6-1$ & 6 & 1 \\
\hline $1-8-7-1$ & 7 & 1 \\
\hline $1-2-1$ & 9 & 1 \\
\hline $1-7-1$ & 10 & 1 \\
\hline $1-4-1$ & 11 & 1 \\
\hline $1-6-1$ & 12 & 1 \\
\hline $1-6-1$ & 14 & 1 \\
\hline $1-3-1$ & 15 & 1 \\
\hline $1-6-1$ & 1 & 2 \\
\hline $1-8-1$ & 2 & 2 \\
\hline $1-2-1$ & 4 & 2 \\
\hline $1-3-1$ & 8 & 2 \\
\hline $1-8-1$ & 9 & 2 \\
\hline $1-6-1$ & 12 & 2 \\
\hline $1-5-1$ & 13 & 2 \\
\hline $1-3-1$ & 2 & 3 \\
\hline $1-2-1$ & 4 & 3 \\
\hline $1-6-9-1$ & 5 & 3 \\
\hline $1-6-1$ & 7 & 3 \\
\hline $1-8-1$ & 8 & 3 \\
\hline $1-8-1$ & 10 & 3 \\
\hline $1-6-1$ & 13 & 3 \\
\hline $1-5-1$ & 14 & 3 \\
\hline $1-3-1$ & 5 & 4 \\
\hline $1-6-1$ & 6 & 4 \\
\hline $1-8-1$ & 11 & 4 \\
\hline $1-8-1$ & 13 & 4 \\
\hline $1-6-1$ & 14 & 4 \\
\hline
\end{tabular}


De acordo com as rotas da Tabela 7, não foram formados transbordos, contudo, houve alguns roteiros formados. Dessa forma, para o teste 2, assim como no teste 1 , foi diminuído o valor do custo de saída da fábrica, a fim de observar se haveriam alterações nas rotas.

Quando o modelo foi rodado novamente com o custo de saída da fábrica reduzido não houve, novamente, a formação do transbordo, sendo formada a rota 1- $8-7-6-1$, ou seja, nesse cenário o modelo criou roteiros maiores. Além disso, não houve aumento no número de veículos utilizados, porém o GAP da melhor solução encontrada diminuiu em relação ao cenário anterior.

Por meio dos 2 testes realizados, pode-se perceber que apesar dos modelos não encontrarem uma solução ótima inteira, devido à sua complexidade, eles possuem um tempo muito bom de resposta, obtendo soluções com GAP's considerados baixos e não demorando muito tempo para que a solução fosse encontrada.

\section{5.}

\section{Análise De Cenários}

Este tópico visa realizar uma comparação entre o cenário proposto (existência de transbordo e roteirização) e o cenário atual da empresa (não ocorre transbordo e nem roteirização), a fim de analisar como se comportam os estoques, bem como os custos de distribuição e estoques, além da quantidade de veículos utilizados.

Para realizar a análise entre os cenários, foi utilizada a configuração do teste 2 do tópico 4.4, com 9 nós, 4 famílias de produtos e 4 períodos de tempo, em função dele ter utilizados 4 períodos, todavia, foram acrescentadas 2 restrições na formulação matemática apresentada no tópico 4.2, as quais seguem expressas abaixo:

$$
\begin{aligned}
& \sum_{c \in V^{c}} \sum_{c c \in V^{c}} \sum_{t \in T} \sum_{n \in N} \sum_{p \in P} w_{c c c t n p}=0 \\
& \sum_{c \in V^{c}} \sum_{c c \in V^{c}} \sum_{n \in N} \sum_{t \in T} x_{c c c n t}=0
\end{aligned}
$$

A equação (4.20) não permite o transporte de produtos entre os CD's e a restrição (4.21) não permite a criação de rotas e de transbordo entre os CD's. 
Assim como no teste 2, o cenário atual da empresa foi rodado durante 100.000 segundos, tendo a melhor solução sido encontrada no instante de 20.283 segundos, de acordo com a Figura 12, e com um GAP de 13,29\%.



Figura 12 - Distribuição das soluções do cenário atual Fonte: Autora (2017).

O cenário atual, possui um valor da função objetivo de $R \$ 133.781,00$, e utilizou 12 veículos no primeiro período, 7 no segundo, 10 no terceiro e 6 no quarto. Em relação aos estoques, ficaram, aproximadamente, 1.004 caixas no estoque, sendo que cada caixa contém 5.000 unidades do produto. Na Figura 13 pode-se se observar a distribuição do estoque por caixas entre os CD's.

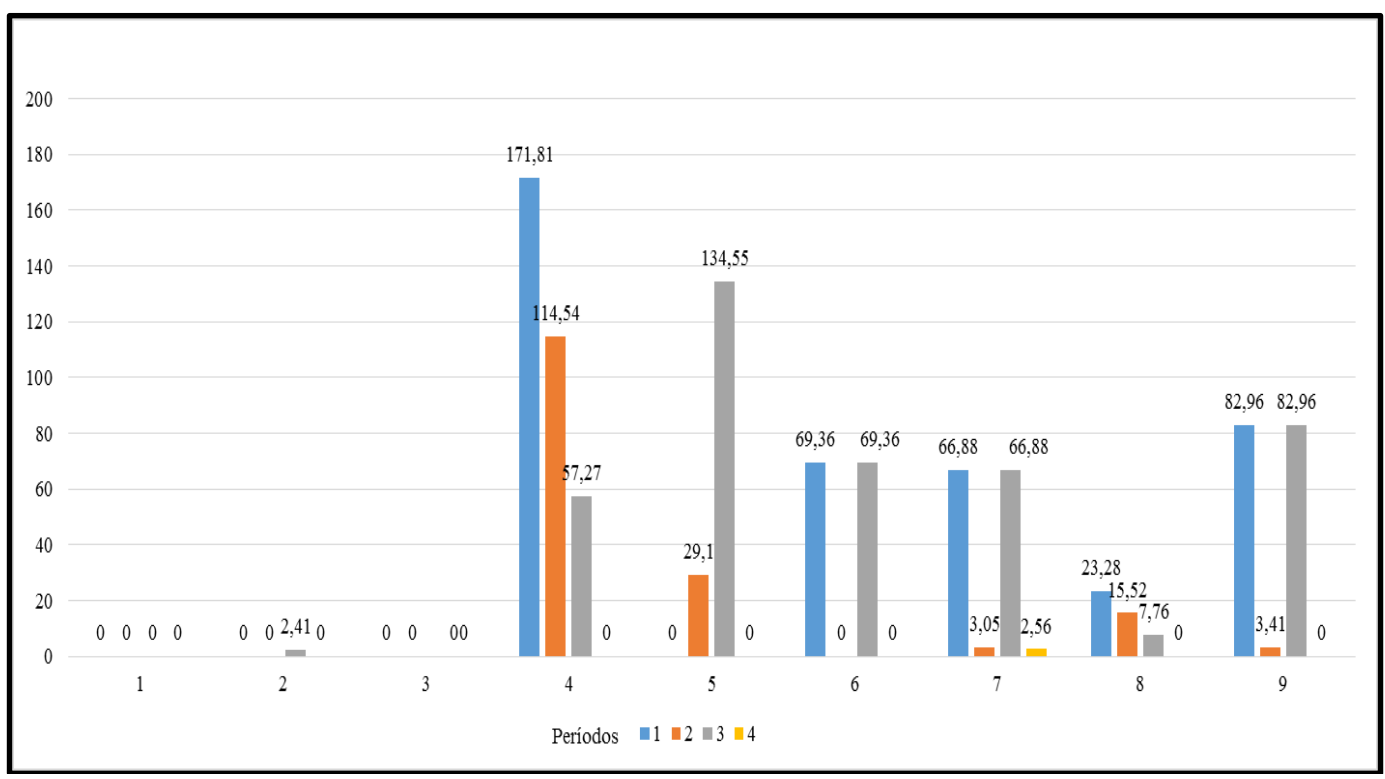

Figura 13 - Distribuição dos estoques no cenário atual Fonte: Autora (2017).

A Tabela 8 apresenta os resultados referente ao custo total, quantidade em estoque e de veículos utilizados, entre outros para uma análise posterior. 
Tabela 8 - Principais resultados comparativos entre o cenário atual e o proposto

\begin{tabular}{lcc}
\hline Indicador & Cenário Atual & Cenário Proposto \\
\hline Custo total (valor da função & $\mathrm{R} \$ 133.781,00$ & $\mathrm{R} \$ 126.535,00$ \\
objetivo) & $13,29 \% \%$ & $8,62 \%$ \\
GAP & 35 & 32 \\
Veículos utilizados & 1.004 & 2.004 \\
Estoque (caixas) & \\
\hline
\end{tabular}

Fonte: Autora (2017).

O valor da função objetivo no cenário atual foi de $R \$ 133.781,00$, utilizando a distribuição direta, ou seja, o caminhão sai da fábrica direto para os CD's. Já no cenário proposto, esse custo foi reduzido para $R \$ 126.535,00$, sendo que nesse cenário é permitida a utilização do transbordo entre os CD's e a criação de roteiros. Essa redução representa, aproximadamente, uma diminuição de 6\% em relação ao valor do cenário atual para 4 períodos com tempo de ciclo igual a 7 dias, ou seja, um mês.

Em relação ao GAP, o valor do cenário proposto é menor do que o do cenário atual da companhia, apesar da complexidade do modelo com transbordo ser maior do que a do modelo com distribuição direta. Também houve redução no número de veículos utilizados quando são comparados o cenário atual e o proposto.

O estoque em caixas do cenário proposto aumentou em relação ao cenário atual, em 1.000 caixas, não representando uma parcela muito grande no custo total do modelo, visto que, apesar do estoque maior no cenário proposto seu custo total ainda é menor do que o da situação atual.

Com base na análise feita neste tópico, pode-se perceber que o modelo proposto pela autora já apresenta uma melhora significativa em relação a situação atual da empresa, mesmo não encontrando uma solução ótima exata para o problema. 


\section{5}

\section{Estudo De Caso}

Neste capítulo, o modelo de IRPT proposto foi utilizado para resolver um caso real de uma empresa produtora e distribuidora de cigarros. Na seção 5.1 a empresa é apresentada, já na seção 5.2 são apresentados os dados utilizados e como eles foram tratados. Na seção 5.3 são apresentados os resultados obtidos e na seção 5.4 é apresentado de que forma as restrições de corte foram implementadas no software Xpress.

\section{1.}

\section{Apresentação Da Empresa}

O presente estudo de caso foi realizado em uma empresa fundada em 25 de abril de 1903, e que hoje é líder no mercado nacional de cigarros. Ela é detentora de seis, das dez marcas de cigarro mais vendidas no Brasil, e produz em torno de 90 bilhões de cigarros anualmente.

A empresa está presente em todo o território nacional, tendo sua matriz localizada no estado do Rio de Janeiro; duas fábricas, uma no Rio Grande do Sul e outra em Minas Gerais; três usinas de processamento de fumo, nos estados do Rio Grande do Sul, Santa Catarina e Paraná, e um Centro de Pesquisas e Desenvolvimento e um Departamento Gráfico também no estado do Rio Grande do Sul. Ela ainda possui 32 CD's espalhados pelo território nacional nos seguintes estados: Santa Catarina, Paraná, Rio Grande do Sul, São Paulo, Mato Grosso, Mato Grosso do Sul, Distrito Federal, Minas Gerais, Goiás, Espírito Santo, Bahia, Sergipe, Pará, Ceará, Paraíba, Amapá, Alagoas, Amazonas, Rio Grande do Norte, Tocantins, Rondônia, Acre, Piauí, Roraima e Maranhão.

A empresa opera desde a fabricação do produto até sua distribuição para os pontos de venda. Dessa forma ela possui 2 formas de distribuição do produto: a distribuição primária, que consiste no transporte do produto da fábrica até os CD's e a distribuição secundária, a qual abrange o transporte dos CD's até os pontos de venda. 
Neste trabalho foi abordado somente a distribuição primária, a qual possui um número menor de pontos de entregado que a secundária, porém os pontos são fixos ao longo dos períodos de tempo e não variáveis como na secundária. Além disso, neste trabalho foi considerada somente a distribuição primária na região sudeste do Brasil composta de 8 CD's mais a Fábrica, pois essa região é responsável por cerca de $60 \%$ da demanda dos produtos (aproximadamente 36 milhões de produtos por mês), além da existência de inconsistências nos dados das outras regiões. Além disso, a empresa opera sua distribuição separada por regiões, logo, foi considerada essa divisão para a delimitação do trabalho.

\section{2.}

\section{Coleta E Tratamento Dos Dados}

O estudo de caso em questão foi desenvolvido a partir de uma fábrica com capacidade de produção infinita, a qual deveria atender 8 Centros de Distribuição com capacidade de armazenamento limitada. Para realizar a entrega para os CD's, a empresa utiliza uma frota de veículos homogêneos (características iguais) com capacidade para 800.000 produtos.

$\mathrm{Na}$ construção do modelo foi utilizado o custo de distribuição entre dois pontos distintos do modelo, sendo que para isso faz-se necessário montar a rede dos CD's, a qual necessita da localização de cada ponto. Dessa forma, foi construída uma matriz origem/destino (O/D) assimétrica, a qual foi construída com as coordenadas (latitude e longitude) fornecidas pela empresa. Com essa matriz O/D e por meio do Google Directions API foram obtidas as distâncias entre os pontos e o tempo de percurso, podendo dessa forma calcular o custo de transporte entre os pontos. Os custos de transporte estão representados na Tabela 9.

Tabela 9 - Custos de transportes (em $\mathrm{R} \$$ )

\begin{tabular}{cccccccccc}
\hline Locais & Fábrica & CD 1 & CD 2 & CD 3 & CD 4 & CD 5 & CD 6 & CD 7 & CD 8 \\
\hline Fábrica & 0 & 3214 & 3256,85 & 4051,14 & 2442,05 & 4881,40 & 3833,16 & 3007,04 & 5219,65 \\
CD 1 & 0 & 0 & 1967,80 & 658,26 & 790,60 & 1720,52 & 515,46 & 344,80 & 3225,10 \\
CD 2 & 0 & 1967,80 & 0 & 2235,98 & 1741,42 & 1570,76 & 2065,32 & 1981,73 & 1870,28 \\
CD 3 & 0 & 644,32 & 2235,98 & 0 & 1421 & 1769,28 & 550,29 & 271,66 & 3276,83 \\
CD 4 & 0 & 776,67 & 1744,90 & 1417,51 & 0 & 2500,67 & 1295,61 & 1100,58 & 3601,25 \\
CD 5 & 0 & 1717,04 & 1570,76 & 1769,28 & 2497,19 & 0 & 1208,54 & 1508,07 & 1790,18 \\
CD 6 & 0 & 515,46 & 2061,84 & 557,25 & 1295,61 & 1208,54 & 0 & 306,49 & 2713,13 \\
CD 7 & 0 & 330,87 & 1988,70 & 264,70 & 1107,54 & 1518,52 & 313,45 & 0 & 3019,62 \\
CD 8 & 0 & 3225,10 & 1870,28 & 3277,35 & 3601,25 & 1793,66 & 2716,61 & 3016,13 & 0 \\
\hline
\end{tabular}

Fonte: Autora (2017). 
Como pode ser observado na Tabela 9, a matriz com os custos de transporte não é simétrica, logo, ela representa melhor os custos de deslocamento entre dois pontos. Além disso, não foram considerados os custos de retorno dos CD's para a Fábrica, pois o frete não está embutido no regresso do caminhão, sendo todos os custos atribuídos somente na saída dos veículos da Fábrica. Esses dados da Tabela 9 são utilizados na função objetivo para calcular o custo de transporte do modelo.

Apesar do modelo não considerar os custos de retorno para a Fábrica, os tempos de retorno foram considerados, a fim de obedecer às restrições (4.11) de tempo de ciclo. Os tempos de deslocamento são apresentados na Tabela 10.

Tabela 10 - Tempos de deslocamento (em dias)

\begin{tabular}{cccccccccc}
\hline Locais & Fábrica & CD 1 & CD 2 & CD 3 & CD 4 & CD 5 & CD 6 & CD 7 & CD 8 \\
\hline Fábrica & 0 & 0,2 & 0,3 & 1 & 0,1 & 1 & 1 & 0,3 & 1 \\
CD 1 & 0,2 & 0 & 0,3 & 0,1 & 0,1 & 0,2 & 0,1 & 0,1 & 1 \\
CD 2 & 0,3 & 0,3 & 0 & 1 & 0,3 & 0,2 & 0,3 & 0,3 & 1 \\
CD 3 & 1 & 0,1 & 1 & 0 & 0,2 & 0,3 & 0,1 & 0,1 & 1 \\
CD 4 & 0,1 & 0,1 & 0,3 & 0,2 & 0 & 1 & 0,2 & 0,2 & 2 \\
CD 5 & 1 & 0,2 & 0,2 & 0,2 & 1 & 0 & 0,2 & 0,2 & 1 \\
CD 6 & 1 & 0,1 & 0,3 & 0,1 & 0,2 & 0,2 & 0 & 0,1 & 1 \\
CD 7 & 0,3 & 0,1 & 0,3 & 0,1 & 0,2 & 0,2 & 0,1 & 0 & 1 \\
CD 8 & 2 & 1 & 1 & 1 & 2 & 1 & 1 & 1 & 0 \\
\hline \multicolumn{7}{c}{ Fonte: Autora (2017). }
\end{tabular}

Outro dado muito importante para o modelo era a demanda de cada CD para cada produto, a qual foi calculada da seguinte forma: como a empresa possui um mix muito grande de produtos, os itens com características semelhantes foram agrupados em famílias e a partir desse agrupamento foi feito o cálculo mensal da demanda de cada família de produto. Como o modelo trabalha com períodos semanais, os dados foram divididos por 4 e assim obteve-se os inputs que foram inseridos no trabalho. Na Tabela 11 é apresentada a demanda das 12 famílias finais de produtos em caixas, as quais contém 5.000 produtos, ou seja, para cada uma unidade da tabela, são considerados 5.000 produtos.

Tabela 11 - Demanda de cada família de produto por CD no período de 7 dias (5.000 unidades)

\begin{tabular}{lcccccccccccc}
\hline Local/Produto & $\mathbf{1}$ & $\mathbf{2}$ & $\mathbf{3}$ & $\mathbf{4}$ & $\mathbf{5}$ & $\mathbf{6}$ & $\mathbf{7}$ & $\mathbf{8}$ & $\mathbf{9}$ & $\mathbf{1 0}$ & $\mathbf{1 1}$ & $\mathbf{1 2}$ \\
\hline CD 1 & 4,25 & 32,80 & 55,38 & 30,83 & 11,00 & 33,51 & 3,35 & 13,27 & 4,65 & 0,67 & 1,81 & 0,32 \\
CD 2 & 4,89 & 37,79 & 63,80 & 35,51 & 12,68 & 38,60 & 3,86 & 15,28 & 5,36 & 0,77 & 2,08 & 0,37 \\
CD 3 & 1,27 & 9,79 & 16,53 & 9,20 & 3,29 & 10,00 & 1,00 & 3,96 & 1,39 & 0,20 & 0,54 & 0,10 \\
CD 4 & 2,98 & 23,01 & 38,85 & 21,62 & 7,72 & 23,50 & 2,35 & 9,31 & 3,26 & 0,47 & 1,27 & 0,22 \\
CD 5 & 12,15 & 93,94 & 158,62 & 88,29 & 31,51 & 95,96 & 9,60 & 37,99 & 13,31 & 1,92 & 5,17 & 0,91 \\
CD 6 & 1,48 & 11,44 & 19,31 & 10,75 & 3,84 & 11,68 & 1,17 & 4,63 & 1,62 & 0,24 & 0,63 & 0,11
\end{tabular}




\begin{tabular}{ccccccccccccc} 
CD 7 & 10,79 & 83,41 & 140,83 & 78,39 & 27,98 & 85,20 & 8,53 & 33,73 & 11,82 & 1,70 & 4,59 & 0,80 \\
CD 8 & 1,84 & 14,19 & 23,95 & 13,33 & 4,76 & 14,49 & 1,45 & 5,74 & 2,01 & 0,29 & 0,78 & 0,14 \\
\hline \multicolumn{1}{c}{ Fonte: Autora (2017). }
\end{tabular}

A demanda de cada produto, expressa na Tabela 11, é um parâmetro que varia em função do local $c$, do produto $p$ e do período $t$. Todavia, no modelo considerou-se a mesma demanda para todos os períodos de tempo, em função de não haver dados suficientes que pudessem expressar a variação da demanda de um período para o outro, dessa forma, o índice $t$ poderia ser retirado desse parâmetro, porém a fim de tornar o modelo mais generalizável e permitir a variação de demanda o índice foi mantido.

Apesar do modelo trabalhar com 12 famílias diferentes do produto, na prática, para o carregamento dos veículos, os produtos são iguais, pois todos ocupam o mesmo volume nos veículos e são agrupados em pacotes iguais. Dessa forma, quando dizemos que o modelo trabalha com múltiplos produtos, significa que eles são diferentes em função de características internas e não em aspectos como embalagem, peso e volume. Tal característica deve ser esclarecida, pois caso houvesse diferenças físicas entres os produtos, elas deveriam ser consideradas na formulação.

Outro dado que também foi considerado foi a capacidade de armazenagem da fábrica e dos CD's, a qual está representada na Tabela 12.

Tabela 12 - Capacidade de armazenagem dos locais (unidades)

\begin{tabular}{cccccccccc}
\hline Local & Fábrica & CD 1 & CD 2 & CD 3 & CD 4 & CD 5 & CD 6 & CD 7 & CD 8 \\
\hline Capacidade & 15.000 & 7.000 & 7.000 & 7.000 & 7.000 & 7.000 & 7.000 & 7.000 & 7.000 \\
\hline \multicolumn{7}{c}{ Fonte: Autora $(2017)}$. & & &
\end{tabular}

\section{3.}

\section{Apresentação E Análise Dos Resultados Obtidos}

Nesta seção o modelo com os dados da empresa foi resolvido em dois cenários: um com 2 períodos de tempo e outro com 4 períodos de tempo. Além disso, foi considerada a frota total da empresa (40 veículos) para cada período de tempo com distribuição para os 8 CD's e existindo a possibilidade de transbordo entre os CD's.

\subsection{1.}

\section{Resultado Com 2 Períodos De Tempo}


Conforme dito na seção 4.4, em função da complexidade do modelo, seria inviável em relação ao tempo esperar que o modelo gerasse uma solução ótima. Diante desse cenário, foram estabelecidos 2 critérios para que o modelo fosse rodado: o primeiro foi que o valor da função objetivo ou fosse ótimo ou tivesse, pelo menos, um GAP inferior a $10 \%$, e o segundo foi que o modelo deveria ser rodado por 100.000 segundos.

O modelo com 2 períodos de tempo produziu sua melhor solução no instante 100.002 segundos com um valor do GAP em $8,08 \%$. As distribuições das soluções ao longo do tempo podem ser observadas na Figura 14.

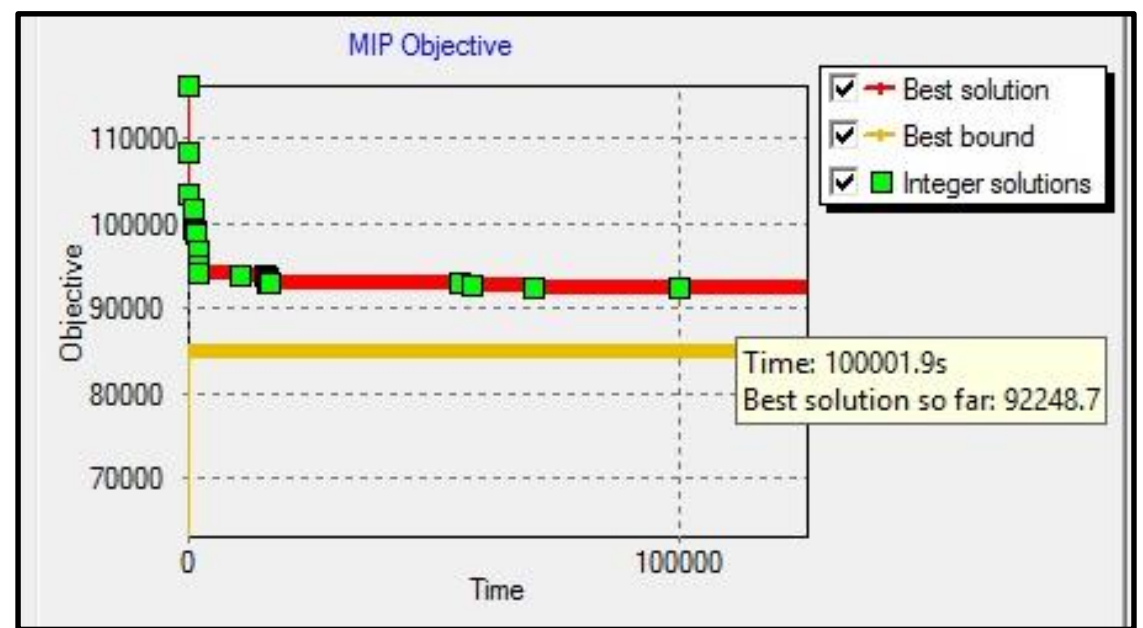

Figura 14 - Distribuição das soluções do modelo com dois períodos de tempo Fonte: Autora (2017).

O modelo gerou 20 soluções viáveis e teve o seu valor fixado em $R$ \$ 92.248,70 reais, em contraposição ao valor ótimo do best bound, de acordo com o software, que seria de $\mathrm{R} \$ 84.795,00$. Em relação ao número de veículos, foram utilizados 15 carros no primeiro período e 9 no segundo.

Em relação ao estoque, sobraram aproximadamente 379 caixas em estoque, ou seja, 1.895 .000 unidades do produto, distribuídos ao longo dos CD's conforme a Figura 15. Já na Figura 16 estão expressos os valores reais dos custos de transporte e estocagem e sua porcentagem em relação ao custo total. 


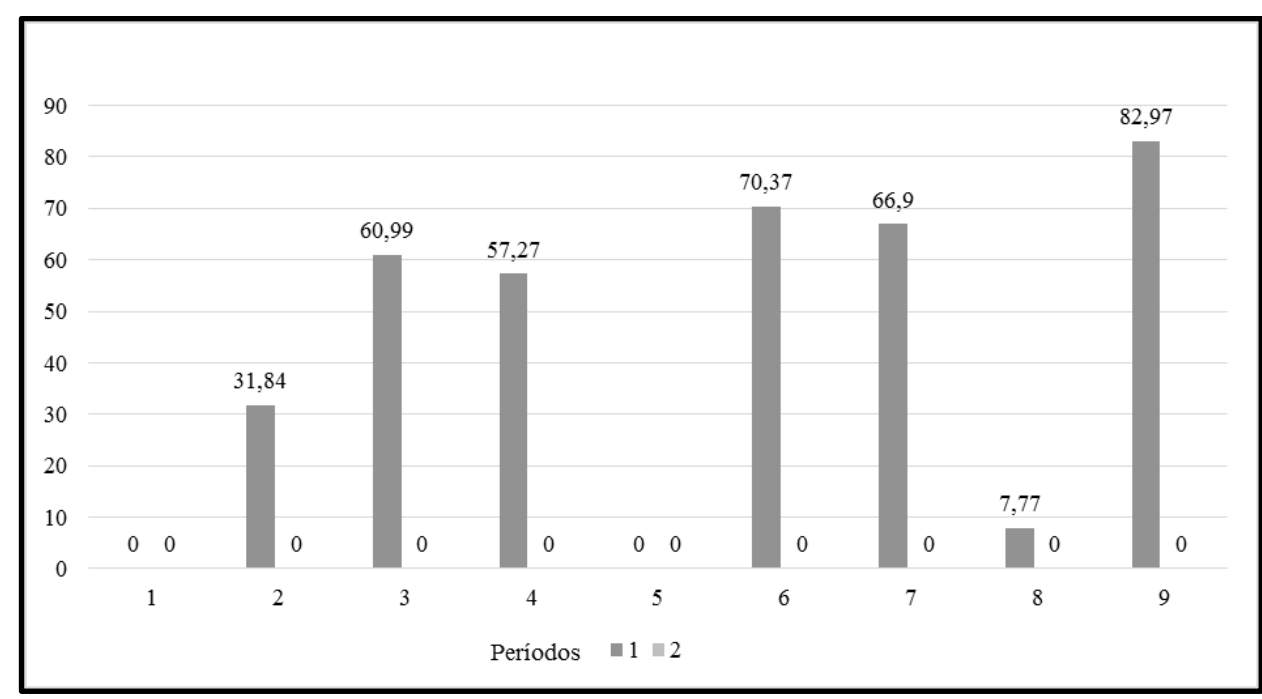

Figura 15 - Estoque no modelo de dois períodos Fonte: Autora (2017).

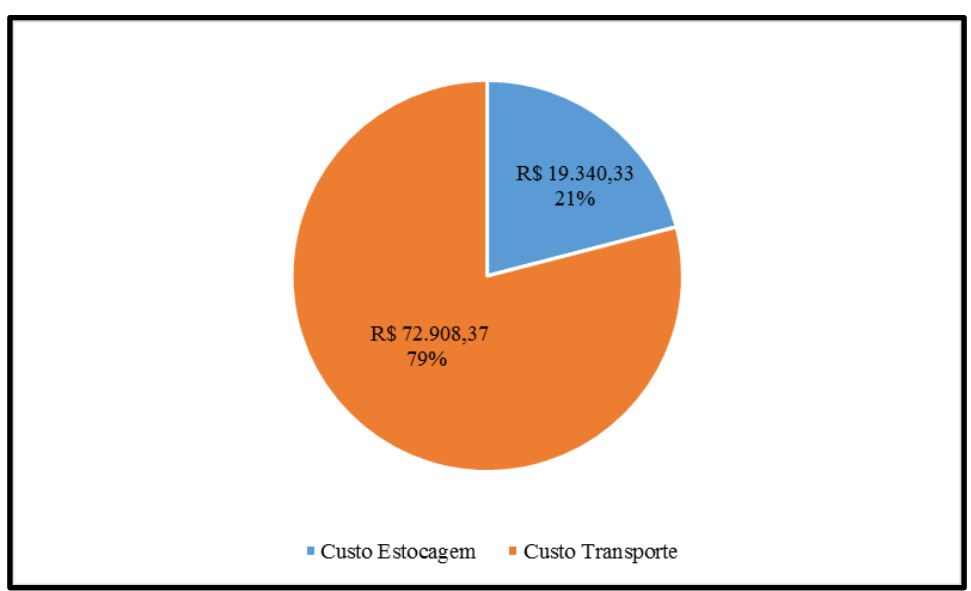

Figura 16 - Representação dos custos do modelo com dois períodos Fonte: Autora (2017).

Como pode ser observado na Figura 16, o custo de transporte representa $79 \%$ do custo total encontrado, contudo, dos 24 veículos que saíram da fábrica, 9 não saíram com sua capacidade máxima, o que significa que ainda existe margem para a redução desse custo ao colocar todos os caminhões saindo da fábrica com carga máxima, colocando uma restrição que obrigue que os caminhões saiam da fábrica com capacidade máxima.

Em relação às rotas, elas podem ser observadas na Tabela 13, sendo que por meio dela é possível perceber que $87,5 \%$ são rotas diretas (Fábrica - CD) e $12,5 \%$ são rotas envolvendo mais de um centro de distribuição.

Tabela 13 - Rotas do modelo com dois períodos de tempo

\begin{tabular}{ccc}
\hline Rotas & Veículo & Período de Tempo \\
\hline $1-8-1$ & 2 & 1 \\
$1-3-1$ & 5 & 1 \\
$1-5-1$ & 7 & 1 \\
$1-6-1$ & 14 & 1
\end{tabular}




\begin{tabular}{ccc}
$1-6-1$ & 15 & 1 \\
$1-7-1$ & 16 & 1 \\
$1-2-1$ & 17 & 1 \\
$1-8-4-1$ & 19 & 1 \\
$1-3-1$ & 20 & 1 \\
$1-9-1$ & 21 & 1 \\
$1-2-4-1$ & 22 & 1 \\
$1-8-1$ & 26 & 1 \\
$1-6-1$ & 33 & 1 \\
$1-8-1$ & 36 & 1 \\
$1-6-9-1$ & 40 & 1 \\
$1-3-1$ & 3 & 2 \\
$1-8-1$ & 5 & 2 \\
$1-6-1$ & 7 & 2 \\
$1-8-1$ & 15 & 2 \\
$1-6-1$ & 16 & 2 \\
$1-2-1$ & 19 & 2 \\
$1-5-1$ & 29 & 2 \\
$1-6-1$ & 32 & 2 \\
$1-8-1$ & 35 & 2 \\
\hline
\end{tabular}

Fonte: Autores (2017).

O fato de não haver ocorrido transbordo nesse cenário, pode ser consequência do valor do custo de saída da fábrica ser muito alto, somado ao fato de não haver custos de se manterem os estoques na fábrica ou nos CD's, dessa forma, o custo de estocagem será muito mais alto do que o custo de transporte, não havendo sentido para o produto sair da fábrica e ser estocado nos CD's para que ocorra transbordo.

Apesar do transbordo não ter ocorrido na situação real da empresa, como o mesmo ocorreu na validação do modelo e respeitou todas as restrições existentes, pode-se afirmar que ele representa a realidade da empresa.

\subsection{2.}

\section{Resultado com quatro períodos de tempo}

Para o modelo com quatro períodos, foram considerados os mesmos critérios utilizados no modelo de dois períodos. Esse modelo produziu seu melhor resultado no instante 71.432 segundos, conforme expresso na Figura 17. 


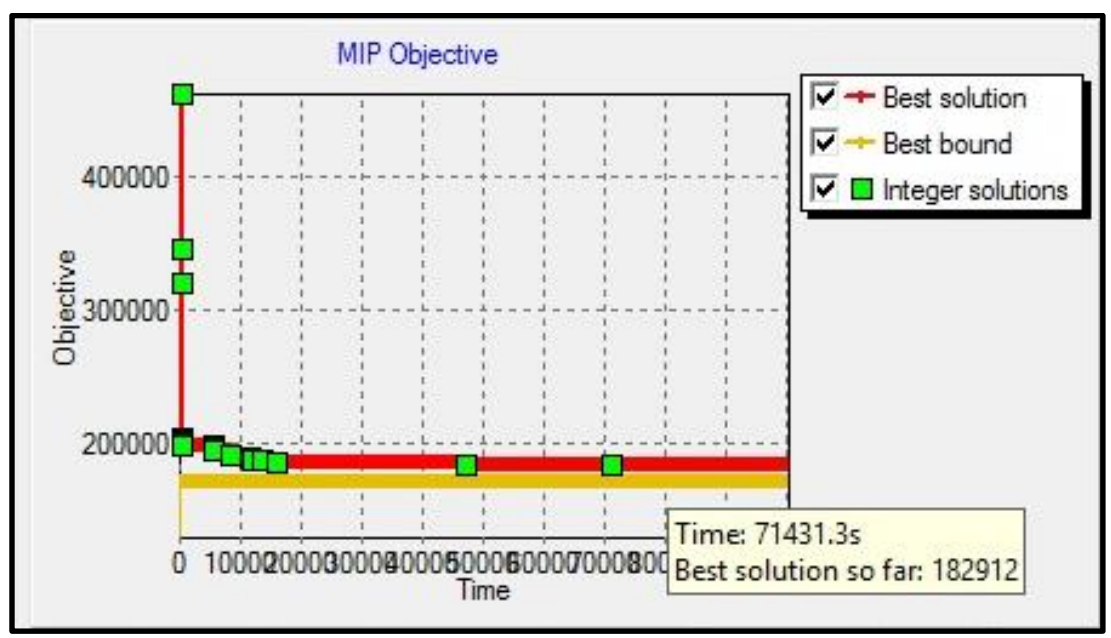

Figura 17 - Distribuição das soluções do modelo com quatro períodos de tempo Fonte: Autora (2017).

Foram geradas 21 soluções viáveis, e o melhor valor encontrado foi de $\mathrm{R} \$$ 182.912,00 com um GAP de 7,38\% em relação ao valor do best bound. Foram utilizados 16 veículos no primeiro período, 10 no segundo, 12 no terceiro e 9 no quarto. De acordo com os resultados por período de tempo, pode-se perceber que a frota da empresa de 40 veículos está superdimensionada, causando grande ociosidade de mais de $50 \%$ da frota.

Em relação ao estoque, sobraram aproximadamente 1.270 caixas de produtos contendo 5.000 unidades em cada caixa, distribuídas pelos CD's e ao longo dos períodos, conforme ilustrado na Figura 18.

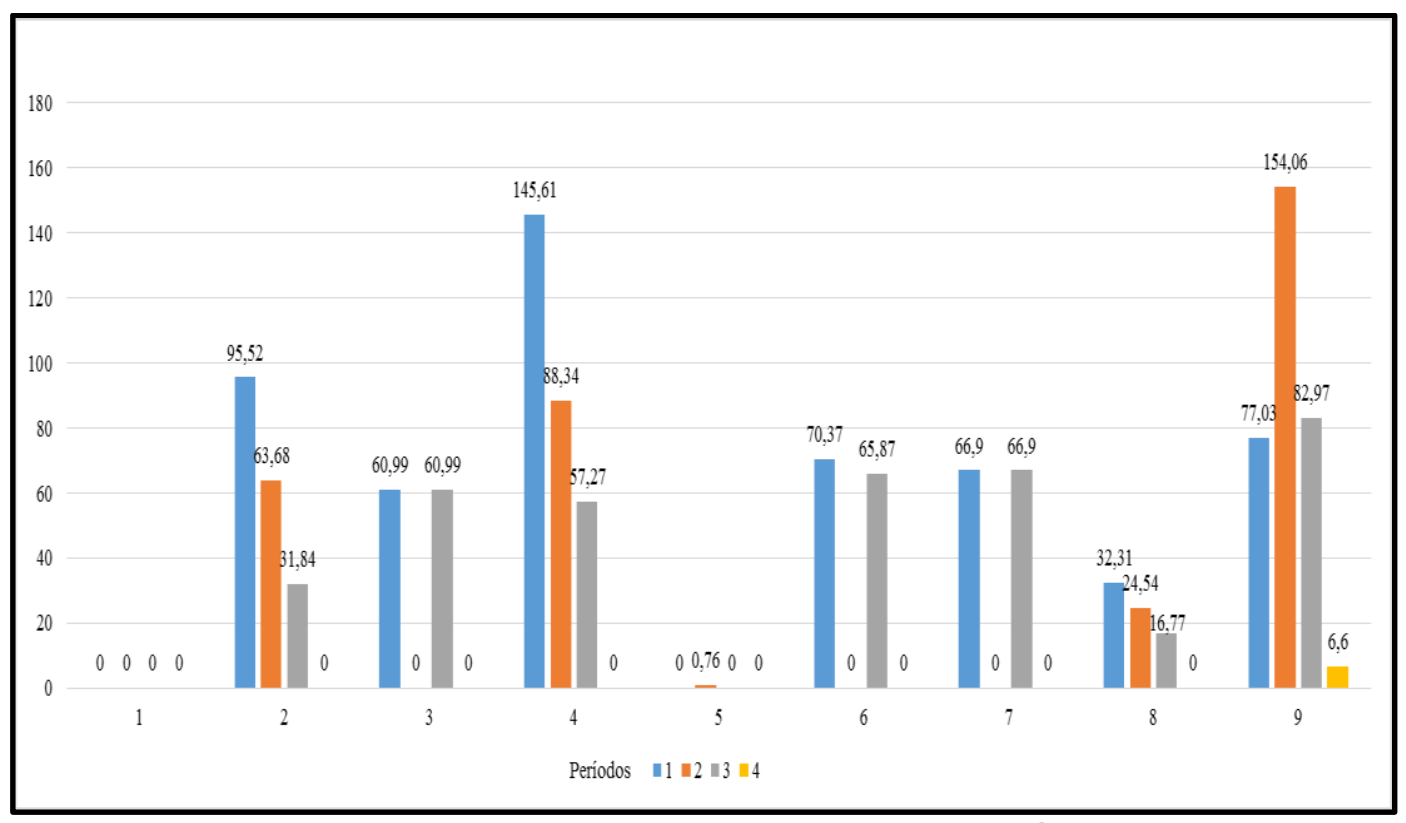

Figura 18 - Estoque no modelo de quatro períodos

Fonte: Autora (2017).

O estoque representa $35 \%$ do custo total encontrado, de acordo com a Figura 19. 


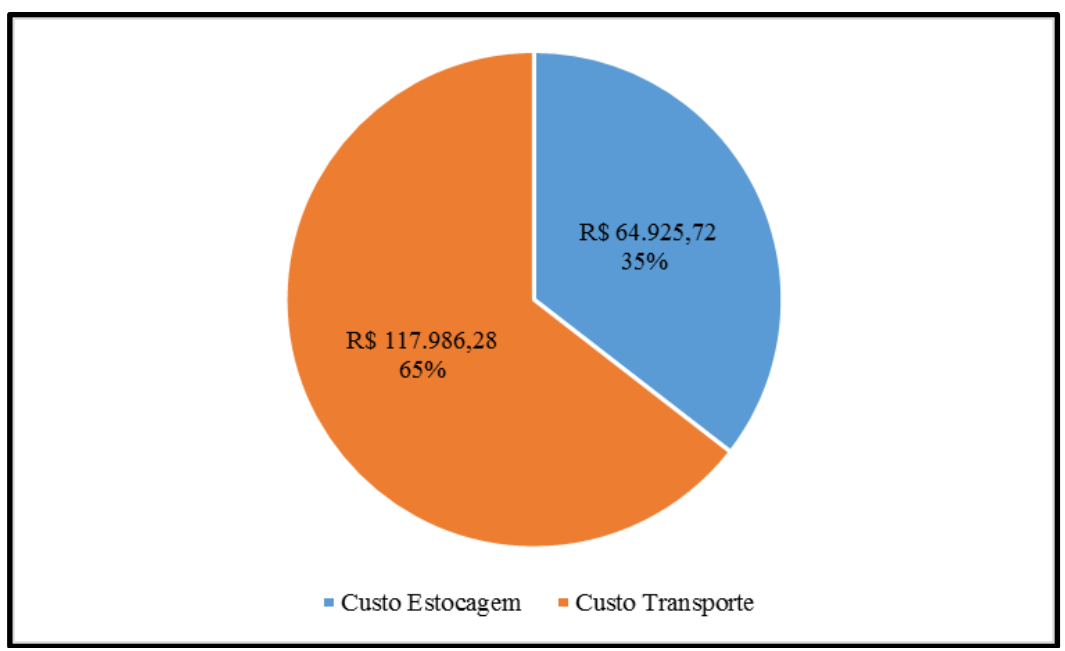

Figura 19 - Representação dos custos do modelo com quatro períodos Fonte: Autora (2017).

Ainda de acordo com a Figura 19, pode-se observar que o transporte representa $65 \%$ do custo total, todavia, assim como no tópico 5.3.1, observou-se que alguns veículos que saíram da fábrica não utilizaram sua capacidade máxima, nesse caso foram 17 dos 47 veículos, mostrando que ainda há espaço para redução desse custo.

Em relação às rotas, elas podem ser observadas na Tabela 14, sendo que por meio dela é possível perceber que $93,6 \%$ são rotas diretas (Fábrica - CD) e $6,4 \%$ são rotas envolvendo mais de um centro de distribuição.

Tabela 14 - Rotas do modelo com quatro períodos de tempo

\begin{tabular}{ccc}
\hline Rotas & Veículo & Período de Tempo \\
\hline $1-8-1$ & 1 & 1 \\
$1-2-1$ & 3 & 1 \\
$1-8-4-1$ & 8 & 1 \\
$1-8-1$ & 15 & 1 \\
$1-6-1$ & 16 & 1 \\
$1-6-1$ & 18 & 1 \\
$1-9-1$ & 20 & 1 \\
$1-7-1$ & 22 & 1 \\
$1-6-1$ & 24 & 1 \\
$1-8-1$ & 28 & 1 \\
$1-6-1$ & 30 & 1 \\
$1-3-1$ & 33 & 1 \\
$1-3-1$ & 35 & 1 \\
$1-4-1$ & 36 & 1 \\
$1-5-1$ & 39 & 1 \\
$1-2-1$ & 40 & 2 \\
$1-6-1$ & 4 & 2 \\
$1-3-1$ & 10 & 2 \\
$1-8-1$ & 19 & 2 \\
$1-6-1$ & 21 & 2 \\
$1-2-1$ & 22 & 2 \\
$1-5-1$ & 24 & 2 \\
$1-6-1$ & 25 & 2 \\
$1-8-1$ & 27 &
\end{tabular}




$\begin{array}{ccc}1-9-1 & 31 & 2 \\ 1-8-1 & 35 & 2 \\ 1-8-1 & 1 & 3 \\ 1-8-1 & 7 & 3 \\ 1-3-1 & 9 & 3 \\ 1-6-9-1 & 13 & 3 \\ 1-6-1 & 14 & 3 \\ 1-6-1 & 16 & 3 \\ 1-5-1 & 27 & 3 \\ 1-6-1 & 29 & 3 \\ 1-8-1 & 33 & 3 \\ 1-3-1 & 34 & 3 \\ 1-2-1 & 35 & 3 \\ 1-7-1 & 40 & 3 \\ 1-6-1 & 7 & 4 \\ 1-2-1 & 9 & 4 \\ 1-8-1 & 17 & 4 \\ 1-8-1 & 22 & 4 \\ 1-5-1 & 23 & 4 \\ 1-8-6-1 & 24 & 4 \\ 1-6-1 & 29 & 4 \\ 1-3-1 & 31 & 4 \\ 1-6-1 & 39 & 4\end{array}$

Fonte: Autores (2017).

Assim como no cenário com dois períodos de tempo, não ocorreu a formação do transbordo, todavia, no cenário com quatro períodos de tempo foram formadas algumas rotas entre os CD's.

\section{4 .}

\section{Restrições De Corte No Xpress}

O software utilizado para o desenvolvimento do trabalho foi o Xpress, o qual possui como interface de modelagem o Mosel. O Mosel é um ambiente de modelagem e resolução de problemas, o qual permite a implementação dos modelos e dos algoritmos de solução em um único ambiente, além disso, sua linguagem é concisa, mais amigável para o usuário e de alto nível, permitindo o desenvolvimento mais rápido.

O software Xpress já possui um exemplo de utilização de SEC's no problema do caixeiro viajante, onde por meio do procedimento break_subtour adicionado ao código inicial do problema, é possível encontrar uma solução. Esse procedimento é ilustrado na Figura 20. 
1. Modelar o problema de acordo com as suas especificaçōes;

2. Resolver o modelo até a otimalidade por meio de um software;

3. Repetir

4. Se a solução não contém subrotas então

5. A solução é ótima

6. Senäo

7. Para cada veículo $n \in N$ e cada período $t \in T$ faça

8. Salvar 0 sucessor de cada cidade na varíável $\mathrm{N}$;

9. Calcular o conjunto de cidades que estão na rota, começando da primeira cidade;

10. Se 0 tamanho da rota corresponde ao conjunto de cidades entäo

11. A solução é ótima

12. Senäo

13. Enumerar todas as subrotas;

14. Encontrar a de menor tamanho;

15. Adicionar a restrição de SEC;

16. Resolver o modelo novamente;

17. Fim se

18. Fim para

19. Fim se

20. Até solução ótima ser encontrada.

Figura 20 - Procedimento de SEC do TSP no software Xpress

Fonte: Autora (2017).

Como o modelo dessa dissertação não corresponde a um TSP clássico, foram necessárias algumas modificações no código do break_subtour para englobar os vários períodos e veículos existentes. Além disso, foi necessário a implantação de um callback no Xpress em função do tempo das restrições SEC's ser exponencial.

Para montar o callback, primeiro, alguns parâmetros do próprio Xpress tiveram que ser desabilitados, como a remoção de colunas, as reduções duais, a remoção de colunas duplicadas e a não criação de variáveis semi-contínuas. Em seguida, foram criados alguns parâmetros para armazenar dados como: as rotas, todos os pontos do modelo, pontos que não estão na rota, contador de cortes, o corte, a identificação do tipo de corte e o tipo da restrição de corte. $\mathrm{O}$ pseudocódigo do modelo juntamente com o callback na forma em que foi implementado no software pode ser observado na Figura 21. 
1. Modelar o problema de acordo com as suas especificações;

2. Resolver o modelo até a otimalidade por meio de um software;

3. Repetir

4. Para cada veículo $n \in N$ e cada período $t \in T$ faça

5. Salvar o sucessor de cada cidade na variável correspondente;

6. Calcular o conjunto de cidades que estão na rota, começando da primeira cidade;

7. Se o tamanho da rota corresponde ao conjunto de cidades então

8. Não existem subrotas para o veículo $n$ no período $t$

9. Senão

10. Enumerar todas as subrotas;

11. Encontrar a menor subrota (todas as cidades com sucessor maior que 0 , mas que não estão na rota);

12. Se 0 tamanho da subrota for maior que 1 então

13. Adicionar a restrição de SEC correspondente ao problema

14. Fim se

15. Fim se

16. Fim para

17. Resolver o modelo novamente;

18. Até todas as subrotas serem eliminadas.

Figura 21 - Pseudocódigo do modelo com o callback

Fonte: Autora (2017).

O pseudocódigo expresso na Figura 21 demonstra a utilização do callback dentro do modelo no software Xpress. O código utilizado tem por objetivo eliminar as possíveis subrotas geradas pelo modelo por meio do callback ao invés do procedimento padrão do Xpress que é o break_subtour. Nesse código, o modelo é resolvido no software para cada veículo existente em todos os períodos de tempo considerados, sendo que se o tamanho da rota é igual ao conjunto de cidades não existem subrotas, todavia, caso existam subrotas, elas são enumeradas e encontra-se a menor e caso ela seja maior que 1, a restrição de SEC utilizada no problema é adicionada ao modelo. Em seguida, o modelo é resolvido novamente até todas as subrotas serem eliminadas.

Após a implementação do callback, observou-se que o modelo não gerou mais as subrotas, além de ter produzido resultados mais rápidos do que somente com o procedimento break_subtour já adaptado ao problema desta dissertação. 


\section{Considerações Finais}

Neste capítulo são apresentadas as considerações acerca dos resultados obtidos e as propostas para trabalhos futuros.

\section{1.}

\section{Considerações Sobre Os Resultados Obtidos}

Esta dissertação estudou o problema de roteirização de veículos com estoque e transbordo, o qual é um tema pouco explorado na literatura de roteirização de veículos. Esse tema é de extrema importância para a indústria, pois considera o abastecimento de um determinado local não apenas por um local de nível anterior na cadeia de suprimentos, mas também por locais de mesmo nível na cadeia. Além disso, ela considerou a existência de diversos produtos e veículos, situação essa que representa a realidade da maioria das indústrias.

Em função da complexidade do problema, não foi possível obter um resultado ótimo utilizando a programação inteira-mista, todavia, foram encontrados valores de GAP considerados baixos, mostrando a eficiência do modelo apresentado. Além disso, ao comparar o cenário real da empresa com o modelo proposto pelo trabalho, foi evidenciado uma redução nos custos totais e redução do número de veículos utilizados.

Em relação ao número de veículos, pode-se observar que a empresa apresenta uma frota superdimensionada para a situação estudada e haveria a possibilidade de reduzir os custos com a redução da frota.

Em relação à pergunta norteadora desta pesquisa, observa-se que os custos de estocagem representam uma parcela menor, porém significativa, dos custos da função objetivo, quando comparados com os custos de distribuição, todavia, os custos de estocagem não devem ser desconsiderados, pois o cigarro é um produto de alta tributação, logo, ele deve sair da fábrica somente se for para ser utilizado. Em relação ao transbordo, ele representa uma parcela pequena do valor final nesse caso específico, contudo, alguns aspectos do modelo, como o alto 
custo de saída da fábrica e grande disponibilidade de veículos, podem ter impactado para essa situação.

\section{2.}

\section{Propostas De Estudos Futuros}

Como não foi encontrada uma solução ótima para o modelo, algumas alterações no modelo podem ser feitas a fim de melhorar a solução encontrada. As alterações sugeridas, bem como propostas para trabalhos futuros seguem abaixo:

- Utilizar uma heurística, a fim de trabalhar com instâncias maiores e obter soluções melhores e em menor tempo;

- Comparar os resultados da programação inteira com a heurística utilizada;

- Colocar veículos heterogêneos no modelo, a fim de avaliar se haverá redução nos custos para a empresa;

- Trabalhar com todos os 32 pontos de distribuição da empresa para gerar um melhor planejamento da distribuição;

- Modelar e resolver o problema da distribuição secundária da empresa, visto que é o problema que impacta diretamente o consumidor;

- Agrupar os modelos de distribuição primária e secundária para melhorar o planejamento. 


\section{Referências bibliográficas}

ALVARENGA, A. C.; NOVAES, A. G. Logística Aplicada -Suprimento e Distribuição Física. 2 ed. São Paulo: Pioneira, 1994.

ARCHETTI, C.; BERTAZZI, L.; LAPORTE, G.; SPERANZA, M. G. A Branch-and-Cut Algorithm for a Vendor-Managed Inventory-Routing Problem. Transportation Science, v. 41, n. 3, p.382-391, ago. 2007.

ARCHETTI, C; BERTAZZI, L.; HERTZ, A. ; SPERANZA, M. G. et al. A Hybrid Heuristic for an Inventory Routing Problem. Informs Journal On Computing, v. 24, n. 1, p.101-116, fev. 2012.

ARCHETTI, C.; SPERANZA, M. G. The inventory routing problem: the value of integration. International Transactions in Operational Research, v. 23, n. 3, p.393-407, 30 nov. 2015.

AZIZI, S.; KAPAK, S. J.; TARHANDEH, F. Physical distribution service quality through iranian convenience stores retailers perspectives: A mixed method approach. Iranian Journal of Management Studies, v. 7, n. 1, p.121-150, jan. 2014.

BALLOU, R. H. Gerenciamento da Cadeia de Suprimentos - Logística Empresarial. 5. ed. Porto Alegre: Bookman, 2006. 616 p.

BERTAZZI, L.; SPERANZA, M. G. Inventory routing problems: an introduction. Euro J Transp Logist, v. 1, n. 4, p.307-326, 27 nov. 2012.

BOWERSOX, D. J.; CLOSS, D. J. Logistical management: the integrated supply chain process. New York: McGraw-Hill, 1996.

CASTIGLIONI, J. Logística Operacional: guia prático. São Paulo: Ética, 2009.

CHANDRA, P.; FISHER, M. L. Coordination of production and distribution planning. European Journal of Operational Research, v. 72, n. 3, p.503517, fev. 1994.

COELHO, L. C.; CORDEAU, J. F.; LAPORTE, G. The inventory-routing problem with transshipment. Computers \& Operations Research, v. 39, n. 11, p.2537-2548, nov. 2012. 
COELHO, L. C.; LAPORTE, G. The exact solution of several classes of inventory-routing problems. Computers \& Operations Research, v. 40, n. 2, p.558-565, fev. 2013a.

COELHO, L. C.; LAPORTE, G. A branch-and-cut algorithm for the multiproduct multi-vehicle inventory-routing problem. International Journal Of Production Research, v. 51, n. 23-24, p.7156-7169, 14 fev. 2013b.

COOPER, M. C.; LAMBERT, D. M.; PAGH, J. D. Supply Chain Management: More Than a New Name for Logistics. The International Journal of Logistics Management, v. 8, n. 1, p.1-14, jan. 1997.

COUNCIL OF SUPPLY CHAIN MANAGEMENT PROFESSIONALS (CSCMP). CSCMP Supply chain management definitions and glossary. Disponível em: <https://cscmp.org/supply-chain-managementdefinitions>. Acesso em: 31 mar. 2016.

CUNHA, C. B. Aspectos Práticos da Aplicação de Modelos de Roteirização de Veículos a Problemas Reais. Transportes (Rio de Janeiro), Rio de Janeiro (RJ), v. 8, n.2, p. 51-74, 2000.

DANTZIG, G.; FULKERSON, R.; JOHNSON, S. Solution of a Large-Scale Traveling-Salesman Problem. Journal Of The Operations Research Society Of America, v. 2, n. 4, p.393-410, nov. 1954.

DANTZIG, G. B.; RAMSER, J. H. The Truck Dispatching Problem. Management Science, v. 6, n. 1, p.80-91, out. 1959.

DESROCHERS, M.; LENSTRA, J. K. ; SAVELSBERGH, M. W. P. A classification scheme for vehicle routing and scheduling problems. European Journal of Operational Research, v. 46, n. 3, p.322332, jun. 1990.

DREXL, M. A note on the separation of subtour elimination constraints in elementary shortest path problems. European Journal Of Operational Research, v. 229, n. 3, p.595-598, set. 2013.

ENOMOTO, L. M. Análise da distribuição física e roteirização em um atacadista do sul de Minas Gerais.2005. 142 f. Dissertação (Mestrado) Curso de Engenharia de Produção, Universidade Federal de Itajubá, Itajubá, 2005.

FEIRING, Bruce R.. Utilizing traveling-Salesman subtours to create sales districts. Engineering Costs And Production Economics, v. 10, n. 3, p.211-215, set. 1986 .

FISHER, M. L.; JAIKUMAR, R. A Generalized Assignment Heuristic for Vehicle Routing. Networks, v.11, n.2, p.109-124, 1979

GAUR, V.; FISHER, M. L. A Periodic Inventory Routing Problem at a Supermarket Chain. Operations Research, v. 52, n. 6, p.813-822, dez. 2004. 
GENDREAU, M.; LAPORTE, G.; SÉGUIN, R. Stochastic vehicle routing. European Journal of Operational Research, v. 88, n. 1, p.3-12, jan. 1996.

GILMORE, D. Achieving transportation excellence. World Trade, Vol. 15 No. 11, p. 36-8, 2002.

GUEMRI, O.; BEKRAR, A.; BELDJILALI, B.; TRENTESAUX, D. GRASPbased heuristic algorithm for the multi-product multi-vehicle inventory routing problem. 4or-q J Oper Res, p.1-28, 22 abr. 2016.

INSTITUTO DE LOGÍSTICA E SUPPLY CHAIN (ILOS). Custos logísticos no Brasil. 2017. Disponível em: < http://www.ilos.com.br/web/analise-demercado/relatorios-de-pesquisa/custos-logisticos-no-brasil/>. Acesso em: 03 abr. 2017.

LAMBERT, D. M.; COOPER, M. C.; PAGH, J. D. Supply Chain Management: Implementation Issues and Research Opportunities. The International Journal of Logistics Management, v. 9, n. 2, p.1-20, jul. 1998.

LAPORTE, G. Generalized Subtour Elimination Constraints and Connectivity Constraints. The Journal Of The Operational Research Society, v. 37, n. 5, p.509-514, maio 1986.

LAPORTE, G. The vehicle routing problem: An overview of exact and approximate algorithms. European Journal of Operational Research, v. 59, n. 3, p.345-358, jun. 1992.

LAPORTE, G. Fifty Years of Vehicle Routing. Transportation Science, v. 43, n. 4, p.408-416, nov. 2009.

LI, J.; CHU, F.; CHEN, H. Coordination of split deliveries in one-warehouse multi-retailer distribution systems. Computers \& Industrial Engineering, v. 60, n. 2, p.291-301, mar. 2011.

LIU, S.; LU, M.; CHUNG, C. A hybrid heuristic method for the periodic inventory routing problem. The International Journal Of Advanced Manufacturing Technology, v. 85, n. 9-12, p.2345-2352, 17 nov. 2015.

MARQUES, V. Utilizando o TMS (transportation management system) para uma gestão eficaz de transportes. 2002. Disponível em: <http://www.ilos.com.br/web/utilizando-o-tms-transportation-managementsystem-para-uma-gestao-eficaz-de-transportes/>. Acesso em: 08 abr. 2016.

MENTZER, J. T.; DEWITT, W.; KEEBLER, J. S.; MIN, S.; NIX, N. W.; SMITH, C. D. ; ZACHARIA, Z. G. Defining supply chain management. Journal of Business Logistics, v. 22, n. 2, p.1-25, set. 2001. 
MIRZAPOUR AL-E-HASHEM, S. M. J.; REKIK, Y. Multi-product multiperiod Inventory Routing Problem with a transshipment option: A green approach. International Journal of Production Economics, v. 157, p.8088, nov. 2014.

NOVAES, A. G. Logística e Gerenciamento da Cadeia de Distribuição. Rio de Janeiro, Elsevier: Editora Campus, 2004.

PATAKI, G. Teaching Integer Programming Formulations Using the Traveling Salesman Problem. Siam Review, v. 45, n. 1, p.116-123, jan. 2003. Society for Industrial \& Applied Mathematics (SIAM).

PATERSON, C.; KIESMÜLLER, G.; TEUNTER, R.; GLAZEBROOK, K. Inventory models with lateral transshipments: A review. European Journal of Operational Research, v. 210, n. 2, p.125-136, abr. 2011.

PFERSCHY, U.; STANĚK, R. Generating subtour elimination constraints for the TSP from pure integer solutions. Central European Journal Of Operations Research, v. 25, n. 1, p.231-260, 17 fev. 2016.

PIRES, S. R. I. Gestão da cadeia de suprimentos e o modelo de consórcio modular. Revista de Administração, São Paulo, v. 33, n. 3, p.5-15, jul./set. 1998.

RAFF, S. Routing and scheduling of vehicles and crews. Computers \& Operations Research, v. 10, n. 2, p.63-211, jan. 1983.

ROSA, R. de A. Gestão de operações e logística I. Brasília: Capes, 2011. $160 \mathrm{p}$.

SANTOS, A. V. N. et al. Estudo da logística de distribuição física de um laticínio utilizando lógica fuzzy. Produção, v. 22, n. 3, p.576-583, ago. 2012.

SHAABANI, H.; KAMALABADI, I. N. An efficient population-based simulated annealing algorithm for the multi-product multi-retailer perishable inventory routing problem. Computers \& Industrial Engineering, v. 99, p.189-201, set. 2016.

SHEN, Q.; CHU, F.; CHEN, H. A Lagrangian relaxation approach for a multimode inventory routing problem with transshipment in crude oil transportation. Computers \& Chemical Engineering, v. 35, n. 10, p.21132123, out. 2011.

SILVA, E. L.; MENEZES, E. M. Metodologia da pesquisa e elaboração de dissertação. 4. ed. Florianópolis: Laboratório de Ensino a Distância da UFSC, 2005.

SLACK, N.; CHAMBERS, S.; JOHNSTON, R. Administração da produção. 3. ed. São Paulo: Atlas, 2009.

SMITH, T. H. C.; SRINIVASAN, V.; THOMPSON, G.I. Computational Performance of Three Subtour Elimination Algorithms for Solving 
Asymmetric Traveling Salesman Problems. Studies In Integer Programming, p.495-506, 1977.

SOYSAL, M.; BLOEMHOF-RUWAARD, J. M.; HAIJEMA, R.; VAN DE VORST, J. G. A. J. Modeling an Inventory Routing Problem for perishable products with environmental considerations and demand uncertainty. International Journal of Production Economics, v. 164, p.118-133, jun. 2015.

THOMAS, D. J.; GRIFFIN, P. M. Coordinated supply chain management. European Journal of Operational Research, v. 94, n. 1, p.1-15, out. 1996.

XING, Y.; GRANT, D. B. Developing a framework for measuring physical distribution service quality of multi-channel and "pure player" internet retailers. International Journal of Retail \& Distribution Management, v. 34, n. 4/5, p.278-289, abr. 2006.

ZENG, A. Z.; ROSSETTI, C. Developing a framework for evaluating the logistics costs in global sourcing processes. International Journal Of Physical Distribution \& Logistics Management, v. 33, n. 9, p.785-803, nov. 2003. 